\title{
Phosphorylated tau fluid biomarker sites recognize earlier neurofibrillary tangle maturity levels in the postmortem Alzheimer's disease brain
}

Christina M. Moloney ${ }^{1}$, Sydney A. Labuzan ${ }^{1}$, Julia E. Crook ${ }^{2}$, Habeeba Siddiqui ${ }^{2}$, Monica Castanedes-Casey ${ }^{1}$, Christian Lachner ${ }^{3,4}$, Ronald C. Petersen ${ }^{5}$, Ranjan Duara ${ }^{6}$, Neill R. Graff-Radford ${ }^{4}$, Dennis W. Dickson ${ }^{1}$, Michelle M. Mielke ${ }^{5,7}$, and Melissa E. Murray ${ }^{1}$

${ }^{1}$ Department of Neuroscience, Mayo Clinic, Jacksonville, FL, USA

${ }^{2}$ Department of Quantitative Health Sciences, Mayo Clinic, Jacksonville, FL, USA

${ }^{3}$ Division of Psychiatry, Mayo Clinic, Jacksonville, FL, USA

${ }^{4}$ Department of Neurology, Mayo Clinic, Jacksonville, FL, USA

${ }^{5}$ Department of Neurology, Mayo Clinic, Rochester, MN, USA

${ }^{6}$ Wien Center for Alzheimer's Disease and Memory Disorders, Mount Sinai Medical Center, Miami Beach, FL, USA

${ }^{7}$ Division of Epidemiology, Department of Quantitative Health Sciences, Mayo Clinic, Rochester, MN, USA

Correspondence should be addressed to:

Melissa E. Murray, PhD.

Associate Professor of Neuroscience

Translational Neuropathology Laboratory

Mayo Clinic

4500 San Pablo Road

Jacksonville FL 32224

Phone: 904-953-1083

Fax: 904-953-7117

E-mail: murray.melissa@mayo.edu

\section{Keywords}

Neuropathology, tau, neurofibrillary tangle, biomarker, Alzheimer's disease, postmortem

\section{Abstract}

Alzheimer's disease (AD) biomarkers have become increasingly more reliable in predicting AD pathology. While phosphorylated tau fluid biomarkers have been studied for over 20 years, there is a lack of deep characterization of these sites in the postmortem brain. Neurofibrillary tangle-bearing neurons, one of the major neuropathologic hallmarks of AD, undergo morphologic changes that mature along a continuum as hyperphosphorylated tau aggregates. To facilitate interpretation of phosphorylated tau sites as an early fluid biomarker, our goal was to characterize which neurofibrillary tangle maturity levels (pretangle, intermediary 1, mature tangle, intermediary 2, and ghost tangle) they recognize. We queried the Florida Autopsied Multi-Ethnic (FLAME) cohort for cases from Braak stages I-VI. We excluded non-AD pathologies and tauopathies. A total of 24 cases, 2 males and 2 females for each Braak stage, were selected. We performed immunohistochemistry on the posterior hippocampus using antibodies directed towards phospho (p) threonine (T) 181, pT205, pT217, and pT231. Slides were digitized to enable quantification of tau burden. To examine differences in regional vulnerability between CA1 and subiculum, we developed a semi-quantitative system to rank the frequency of each neurofibrillary tangle maturity level. We identified all neurofibrillary tangle maturity levels at least once for each phosphorylated tau site. Primarily earlier neurofibrillary tangle maturity levels (pretangle, intermediary 1 , mature tangle) were recognized for all phosphorylated tau sites. There was an increase in tau burden in the subiculum compared to CA1; however, this was attenuated compared to thioflavin-S positive tangle counts. On a global scale, tau burden generally increased with each Braak stage. These results provide neurobiologic evidence that these phosphorylated tau fluid biomarker sites are present during earlier neurofibrillary tangle maturity levels. This may help explain why these phosphorylated tau biomarker sites are observed before symptom onset in fluids.
\end{abstract}




\section{Introduction}

Alzheimer's disease (AD) is a neurodegenerative disorder characterized by two hallmark pathologies: plaques composed of amyloid- $\beta$ and neurofibrillary tangles composed of hyperphosphorylated tau [1, 2, 49]. Amyloid- $\beta$ plaques reside outside the neuron whereas neurofibrillary tangles accumulate inside the neuron. Neurofibrillary tangles have a lifespan that progresses through three major levels: pretangles, mature tangles, and ghost tangles [42]. Pretangles contain diffuse or granular hyperphosphorylated tau in otherwise morphologically normal neurons with perinuclear tau accumulation often observed [6]. Mature tangles are intensely stained bundles of fibers that take the shape of the neuron they occupy. The nucleus may appear shrunken and misplaced towards the cell membrane [1, 2, 49]. Ghost tangles are the remnants of mature tangles once the neurons have died and are recognized by faintly stained bundles of fibers with no associated nucleus [1, 2, 49]. Additionally, intermediaries exist between these three neurofibrillary tangle maturity levels [42]. The first intermediary, between pretangles and mature tangles, has intensely stained tau accumulation in the neuron, but lacks the fullness of the mature tangle. These were previously described as nucleation sites [33] that may represent a nidus of fibrillization. The second intermediary, between mature tangles and ghost tangles, appears robustly stained like mature tangles but lacks a nucleus.

Biomarkers are an important tool that have become increasingly more reliable in measuring AD pathology in vivo [20]. One such biomarker is positron emission tomography (PET), which can identify patients with increased tau or amyloid- $\beta$ levels. PET imaging can lead to a more informed antemortem diagnosis and provide spatial information of which regions have a high neuropathologic burden $[31,44]$. However, disadvantages to PET imaging include cost, availability, and patient exposure, albeit minimal, to radioactivity. Alternatively, fluid biomarkers are useful in identifying changes in amyloid- $\beta$ and tau in patients without the use of radioactivity [40]; however, these biomarkers lack spatial information. Over 20 years ago, total tau [38, 56, 59] and phosphorylated tau [11] were found increased in cerebrospinal fluid of AD patients compared to controls. Multiple tau phosphorylation (p) sites are elevated in these fluid biomarkers, including at threonine (T) 181 [11, 57], pT205 [9], pT217 [7, 39], and pT231 [11, 24]. Evaluation of the temporal sequence of cerebrospinal fluid tau biomarkers in dominantly inherited AD identified pT217 as increasing first, followed by pT181, and finally pT205 [8]. Following the successful translation of cerebrospinal fluid assays to plasma [4, 41, 45, 52], one study suggested pT231 levels may increase earlier than pT181 [4]. With the increasing evidence that tau fluid biomarkers may be more sensitive to the earlier changes in AD pathology, we sought to test the hypothesis that these phosphorylation sites recognize earlier neurofibrillary tangle maturity levels. Thus, our first goal was to immunohistochemically characterize the neurofibrillary tangle maturity levels recognized by these four fluid biomarker phosphorylated tau sites: pT181, pT205, pT217, and pT231. Secondly, we sought to examine regional differences leveraging the vulnerability of cornu ammonis (CA) 1 and subiculum $[43,46]$ using digital pathology to quantify tau burden. Lastly, we sought to identify changes in the phosphorylated tau sites based on global severity measured by Braak stage $[12,13]$ to evaluate shifting recognition of neurofibrillary tangle maturity levels.

\section{Materials and Methods}

Cohort selection

The Florida Autopsied Multi-Ethnic (FLAME) cohort [28, 47], as of May 27, 2020, was queried to identify cases with a spectrum of

\begin{tabular}{|c|c|c|c|c|c|c|c|}
\hline Characteristic & Braak I & Braak II & Braak III & Braak IV & Braak V & Braak VI & p-value \\
\hline Number & 4 & 4 & 4 & 4 & 4 & 4 & \\
\hline Age at death, year & $87(79,93)$ & $80(71,84)$ & $89(87,93)$ & $84(82,93)$ & $86(82,90)$ & $79(71,84)$ & 0.041 \\
\hline Females $(\%)$ & $2 / 4(50 \%)$ & $2 / 4(50 \%)$ & $2 / 4(50 \%)$ & $2 / 4(50 \%)$ & $2 / 4(50 \%)$ & $2 / 4(50 \%)$ & 1.000 \\
\hline$A P O E \varepsilon 4+(\%)$ & $0 / 4(0 \%)$ & $0 / 4(0 \%)$ & $0 / 4(0 \%)$ & $2 / 4(50 \%)$ & $3 / 4(75 \%)$ & $2 / 4(50 \%)$ & 0.058 \\
\hline Brain weight, g & $1305(960,1440)$ & $1090(1060,1220)$ & $1140(1000,1320)$ & $1050(1020,1340)$ & $1030(960,1160)$ & $890(760,1100)$ & 0.002 \\
\hline \multicolumn{8}{|c|}{ Digital pathology findings } \\
\hline \multicolumn{8}{|c|}{ Whole hippocampus measures } \\
\hline Area $\left(\mathrm{mm}^{2}\right)$ & $44(43,49)$ & $45(39,60)$ & $50(35,67)$ & $48(35,67)$ & $31(28,54)$ & $34(31,40)$ & 0.034 \\
\hline \multicolumn{8}{|l|}{ Positive Pixel Count } \\
\hline pT181 burden, $\%$ & $1.6(0.50,7.9)$ & $2.9(0.47,7.7)$ & $1.7(0.64,4.5)$ & $4.1(2.8,8.6)$ & $7.2(1.8,8.9)$ & $13(10,14)$ & $<0.001$ \\
\hline pT205 burden, $\%$ & $0.52(0.15,0.82)$ & $0.19(0.065,4.7)$ & $2.3(1.2,5.8)$ & $10(2.7,13)$ & $9.4(6.7,12)$ & $9.5(6.8,12)$ & $<0.001$ \\
\hline pT217 burden, $\%$ & $0.78(0.38,2.0)$ & $0.70(0.090,7.4)$ & $4.7(2.9,10)$ & $16(5.6,18)$ & $13(12,17)$ & $20(8.3,23)$ & $<0.001$ \\
\hline pT231 burden, $\%$ & $0.25(0.17,0.36)$ & $0.11(0.048,2.3)$ & $1.5(0.93,3.5)$ & $6.6(2.9,8.1)$ & $8.3(4.9,13)$ & $12(6.4,17)$ & $<0.001$ \\
\hline \multicolumn{8}{|l|}{ CA1 measures } \\
\hline Thioflavin S counts & $0(0,1)$ & $1(0,1)$ & $2(1,4)$ & $5(2,10)$ & $10(4,25)$ & $22(6,30)$ & $<0.001$ \\
\hline \multicolumn{8}{|l|}{ Positive Pixel Count } \\
\hline pT181 burden, \% & $0.95(0.24,3.5)$ & $1.4(0.19,3.6)$ & $1.8(0.58,3.2)$ & $3.8(3.5,12)$ & $7.3(2.4,11)$ & $14(5.8,18)$ & $<0.001$ \\
\hline pT205 burden, $\%$ & $0.70(0.25,2.5)$ & $0.21(0.066,6.0)$ & $3.1(1.7,8.8)$ & $13(3.8,20)$ & $15(11,17)$ & $13(8.9,18)$ & $<0.001$ \\
\hline pT217 burden, $\%$ & $0.78(0.60,3.0)$ & $0.37(0.073,9.6)$ & $6.2(3.9,17)$ & $25(7.1,28)$ & $19(17,25)$ & $30(11,33)$ & $<0.001$ \\
\hline pT231 burden, $\%$ & $0.27(0.24,0.70)$ & $0.11(0.046,3.1)$ & $2.2(1.4,6.5)$ & $10(3.6,15)$ & $14(6.4,21)$ & $17(7.9,28)$ & $<0.001$ \\
\hline \multicolumn{8}{|l|}{ Subiculum measures } \\
\hline Thioflavin S counts & $0(0,1)$ & $0(0,1)$ & $2(1,4)$ & $8(6,17)$ & $22(8,40)$ & $40(25,55)$ & $<0.001$ \\
\hline \multicolumn{8}{|l|}{ Positive Pixel Count } \\
\hline pT181 burden, \% & $1.4(0.37,7.4)$ & $2.8(0.26,4.7)$ & $2.7(0.91,4.4)$ & $6.7(4.6,13)$ & $9.0(3.5,11)$ & $21(13,23)$ & $<0.001$ \\
\hline pT205 burden, $\%$ & $1.1(0.24,1.2)$ & $0.24(0.064,9.9)$ & $4.9(3.1,12)$ & $19(6.8,20)$ & $18(11,21)$ & $18(11,22)$ & $<0.001$ \\
\hline pT217 burden, $\%$ & $1.5(0.64,2.4)$ & $0.64(0.082,16)$ & $10(6.9,20)$ & $31(13,39)$ & $23(17,34)$ & $38(16,43)$ & $<0.001$ \\
\hline
\end{tabular}


bioRxiv preprint doi: https://doi.org/10.1101/2021.08.25.457363; this version posted August 26, 2021. The copyright holder for this preprint (which was not certified by peer review) is the author/funder, who has granted bioRxiv a license to display the preprint in perpetuity. It is made available under aCC-BY-NC 4.0 International license.

Table 2. Antibody information

\begin{tabular}{|c|c|c|c|c|c|c|c|c|c|c|}
\hline Antibody & Epitope & Vendor & Catalog \# & Species & Clonality & Isotype & RRID & Dilution & $\begin{array}{l}\text { Antigen } \\
\text { Retrieval }\end{array}$ & Ref \\
\hline pT205 & pT205 & Thermo Fisher Scientific & 44-738G & Rabbit & Polyclonal & IgG & AB_2533738 & $1: 2,500$ & $\mathrm{H}_{2} \mathrm{O}$ steam & \\
\hline AT180 & pT231 & Thermo Fisher Scientific & MN1040 & Mouse & Monoclonal & $\operatorname{IgG} 1 \kappa$ & AB_223649 & $1: 5,000$ & $\mathrm{H}_{2} \mathrm{O}$ steam & [17] \\
\hline
\end{tabular}

AD neuropathology. Cases with significant non-AD neurodegenerative pathology (frontotemporal lobar degeneration, amyotrophic lateral sclerosis, hippocampal sclerosis, Lewy body disease, amygdala predominant Lewy bodies, multiple system atrophy, Creutzfeldt-Jakob disease) and non-AD tauopathies (progressive supranuclear palsy, corticobasal degeneration, Pick's disease, globular glial tauopathies, MAPT mutation carriers) were excluded. Cases with exhausted paraffin embedded blocks of the posterior hippocampus were also excluded. Ethnoracial minorities were given higher priority when selecting cases as these groups have historically been excluded from studies. We selected 2 males and 2 females for each Braak stage I, II, III, IV, V, and VI [12, 13]. For Braak stages IV-VI, only AD cases with a typical AD subtype were selected [43]. A summary of cases included in this study is found in Supplementary Table 1. The final cohort included 24 cases (Table 1). There were 2 males and 2 females per Braak stage. There was 1 black decedent (Braak stage III), and 5 Hispanic decedents (1 Braak stage I, 1 Braak stage III, 2 Braak stage $\mathrm{V}, 1$ Braak stage VI). There were 7 APOE $\varepsilon 4$ positive cases (2 Braak stage IV, 3 Braak stage V, 2 Braak stage VI).

Tissue sampling and histology

Autopsied brains were evaluated and sampled using the Dickson sampling scheme, as previously described [47]. Formalin-fixed, paraffin-embedded tissue sections of the posterior hippocampus were cut at $5 \mu \mathrm{m}$ thick and mounted on positively charged glass slides. Thioflavin-S was used to assess AD pathology to assign AD subtype [43], Braak stage [13], and Thal phase [53]. Primary age related tauopathy (PART) was diagnosed if cases were Braak stage $\leq \mathrm{IV}$ with a "definite" classification if Thal phase 0 or a "possible" classification if Thal phase 1-2 [14]. Cases not meeting recommended PART criteria who were Thal phase $>2$ were diagnosed as pathological aging if significant cortical amyloid- $\beta$ pathology ( $\geq 30$ amyloid- $\beta$ plaques per 10x field) with minimal neurofibrillary tangle pathology (Braak stage <IV) was observed [15]. Further, these Braak <IV cases not meeting recommended PART criteria who were Thal phase $>2$ with non-significant cortical amyloid- $\beta$ pathology $(<30$ amyloid- $\beta$ plaques per $10 x$ field) were diagnosed as senile change [31]. Aging-related tau astrogliopathy (ARTAG) was diagnosed if cases had thornshaped or granular/fuzzy astrocytes [25]. Significant vascular disease was diagnosed in the presence of two or more of the following pathologies: severe cerebral amyloid angiopathy, moderate-to-severe white matter rarefaction, hippocampus sclerosis of a vascular etiology, large infarct, lacunar infarct, microinfarct, or white matter infarct.

Sections were stained with hematoxylin and eosin (H\&E) using standard methods. For neurofibrillary tangle counts, sections were stained with thioflavin-S. Neurofibrillary tangles (mature tangles and ghost tangles) were collectively counted in a 40x field of view $\left(0.125 \mathrm{~mm}^{2}\right)$ with highest burden in the CA1 subsector of the hippocampus and the subiculum using the Olympus BH2 fluorescence microscope. Immunohistochemistry using AT270 (pT181), pT205, pT217, and AT180 (pT231) antibodies was performed on the Thermo Scientific Lab Vision Autostainer 480S. Specifications and vendor information for each antibody is found in Table 2. All epitopes fall within the proline rich region (Fig. 1), sometimes described as mid-domain, which lies $\mathrm{N}$-terminal to the microtubule binding region [19]. Sections were developed with the developing kit (Biocare Medical, catalog \#M3M530L [mouse] or M3R531L [rabbit]). Regarding nomenclature, the current study will use "p $\mathrm{T}$ " when describing immunohistochemical evidence from the phosphorylated threonine site and " $p$-tau" when discussing relevant information from the fluid biomarker literature on phosphorylated tau.

\section{Digital pathology}

H\&E and immunohistochemically stained slides were digitally scanned at 20x using the Aperio AT2 scanner. Using ImageScope (Leica Biosystems, version 12.4.3.5008), digitally scanned slides were annotated with the pen tool to trace the CA1 and subiculum. The superior border was defined as the boundary between the lacunosum and radiatum layers. The inferior border was defined as the boundary between the pyramidal layer and alveus. The border between CA1 and subiculum was defined as halfway between the dentate gyrus length. For consistency using landmarks, the CA1 was traced from the CA1/subiculum border to the ventricle. The whole hippocampus was annotated, including the alveus, excluding the fornix, and allowing the rise of the subiculum into the presubiculum to come to a natural endpoint. Hippocampal area (per $\mathrm{mm}^{2}$ ) was traced on each of the immunohistochemically stained sections and averaged to obtain a final area. H\&E stained sections facilitate recognition of neuroanatomic boundaries and are thus traced first as a template for subsequent tracing on immunohistochemical slides. For all scans, dust and artifacts were excluded using the negative pen tool.

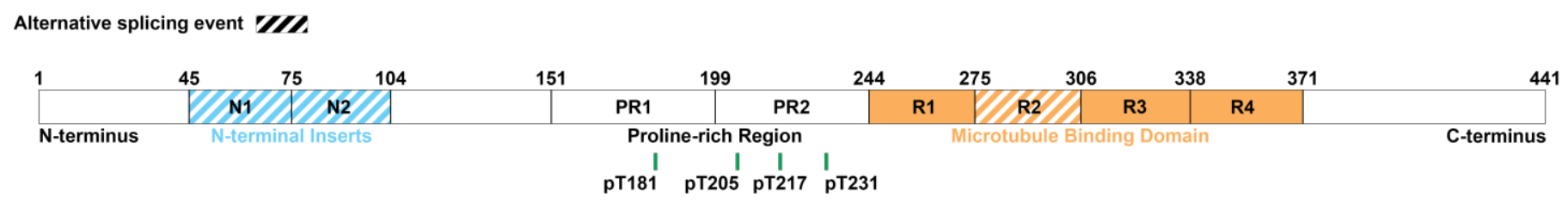

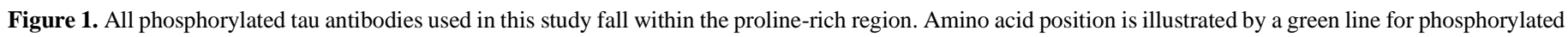
threonine (pT) at 181, 205, 217, and 231. Figure adapted from [42]. 
Batch analysis of the scans was completed using eSlideManager (Leica Biosystems). For burden analysis, digitized slides were analyzed with color deconvolution (v9) (Supplementary Table 2) and positive pixel count (v9) (Supplementary Table 3) macros custom designed for each antibody to recognize the 3,3'-diaminobenzidine staining on the tissue and to exclude background. Positive pixel count results will be described in this study; for color deconvolution results, please see Supplementary Table 4.

Neurofibrillary tangle maturity level classifications

Neurofibrillary tangles were classified into the following maturity levels: pretangle, intermediary 1 tangle, mature tangle, intermediary 2 tangle, and ghost tangle. Pretangles were identified by diffuse or granular staining of phosphorylated tau and could have perinuclear accumulation of tau. Pretangles were less intensely stained tau than mature tangles. Intermediary 1 tangles were identified with intensely stained aggregates that did not fill the entire neuron. These aggregates may be round or fibrillar in appearance. Mature tangles were identified by intense staining of phosphorylated tau throughout most, if not all the neuron, with an associated nucleus that was often displaced or shrunken in appearance. Intermediary 2 tangles were identified with intense staining of phosphorylated tau throughout the entire neuron but lack a nucleus. Ghost tangles were identified with weaker staining of phosphorylated tau compared to mature tangles in structures that appear to be loosely arranged bundles of fibers with no associated nucleus.

\section{Neurofibrillary tangle maturity semi-quantification}

Neurofibrillary tangle maturity levels were semi-quantified in the annotated regions in the CA1 and subiculum using a grading system: absence, rare, and presence. Absence referred to no pathology that resembled a maturity level. Rare referred to 1-5 individual tangles of a certain maturity level. Presence referred to greater than 5 tangles of a certain maturity level. For quantification, we assigned each frequency a value: absence $=0$, rare $=0.5$, presence $=1$. Values from cases in each Braak stage per phosphorylated tau site were added together.

\section{Statistical analysis}

To compare the four tau biomarker sites to each other, we analyzed all scans with both positive pixel count and color deconvolution (Supplemental Fig. 1). Continuous values are reported as median (interquartile range $\left[25^{\text {th }}, 75^{\text {th }}\right]$ ). A permutation test with Kendall's Tau was used to test differences of continuous values between Braak stages. Spearman correlation was used for the whole hippocampal area measures with tau burden. A Pearson's chi-squared test was used to test differences of categorical values between Braak stages. P-values $<0.05$ were considered statistically significant. For comparing CA1 and subiculum burden, a simple linear regression was performed using GraphPad Prism and ratio was assessed by slope of the best fit line (version 9.0.0). All other statistical analyses were performed using R (version 4.0.3).

\section{Figure development}

Figures were created using Adobe Photoshop CC 2018 (version 19.1.6). Snapshots of 10x and 20x immunohistochemically stained sections were acquired using ImageScope (Leica
Biosystems, version 12.4.3.5008). Thioflavin-S stained slides were digitally scanned using the Pannoramic 250 Flash III scanner (3DHistech) and snapshots of a 20x view of the CA1 and subiculum were taken using the CaseViewer software (3DHistech, version 2.3.0.99276) after digital alteration to
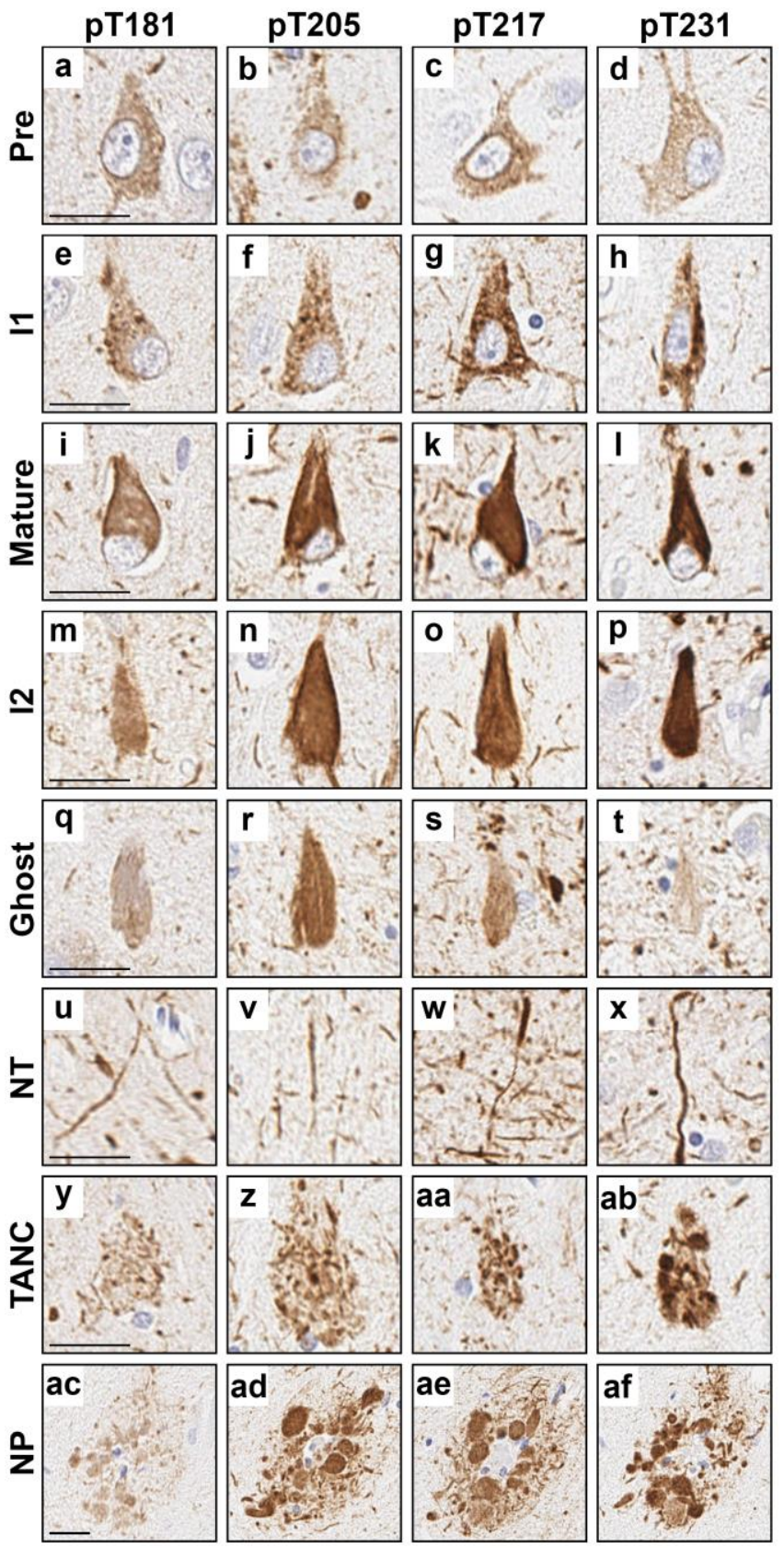

Figure 2. Examples of neurofibrillary tangle maturity levels and neuritic pathology observed with each phosphorylated tau site. a-d Pretangles, e-h intermediary 1 (I1), i-l mature tangles, m-p intermediary 2 (I2), q-t ghost tangles, $\mathbf{u}-\mathbf{x}$ neuropil threads (NT), $\mathbf{y}$-ab tangle associated neuritic clusters (TANC), and ac-af neuritic plaques (NP) were observed for all phosphorylated tau sites. a, e, i, $\mathbf{m}, \mathbf{q}, \mathbf{u}, \mathbf{y}$, and ac were stained with the pT181 antibody. b, f, j, n, r, v, z, and ad were stained with the pT205 antibody. c, g, $\mathbf{k , ~} \mathbf{o}, \mathbf{s}, \mathbf{w}, \mathbf{a a}$, and ae were stained with the pT217 antibody. d, h, l, p, t, x, ab, and af were stained with the pT231 antibody. All images were taken in the CA1 subsector of the hippocampus except for $\mathbf{q}, \mathbf{r}$, and $\mathbf{t}$ which were taken in the subiculum. $\mathbf{a}, \mathbf{e}, \mathbf{i}, \mathbf{l}, \mathbf{t}, \mathbf{k}$, and $\mathbf{a b}$ are from case 18 . $\mathbf{b}$ is from case $9 . \mathbf{c}$ is from case 14. d, $\mathbf{h}, \mathbf{n}$, and $\mathbf{a c - a f}$ are from case 17. f, j, $\mathbf{v}$, and $\mathbf{z}$ are from case 16. $\mathbf{g , ~} \mathbf{q}, \mathbf{r}$, and $\mathbf{a a}$ are from case 13. $\mathbf{k}, \mathbf{s}, \mathbf{u}, \mathbf{w}$, and $\mathbf{y}$ are from case $15 . \mathbf{m}, \mathbf{p}$, and $\mathbf{x}$ are from case 23. $\mathbf{o}$ is from case 22. Scale bar measures $25 \mu \mathrm{m}$. 
bioRxiv preprint doi: https://doi.org/10.1101/2021.08.25.457363; this version posted Auqust 26, 2021. The copyright holder for this preprint (which was not certified by peer review) is the author/funder, who has granted bioRxiv a license to display the preprint in perpetuity. It is made available under aCC-BY-NC 4.0 International license.

a

\begin{tabular}{|c|c|c|c|c|c|c|c|c|c|c|c|c|c|c|c|c|c|c|c|c|c|}
\hline \multirow{3}{*}{$\begin{array}{l}\text { Braak } \\
\text { Stage }\end{array}$} & \multirow{3}{*}{$\begin{array}{c}\text { Region } \\
\text { pTau } \\
\text { Sex }\end{array}$} & \multicolumn{9}{|c|}{ CA1 } & \multicolumn{11}{|c|}{ Sub } \\
\hline & & \multicolumn{2}{|c|}{ PT181 } & \multicolumn{2}{|c|}{ pT205 } & \multicolumn{2}{|c|}{ pT217 } & & \multicolumn{2}{|c|}{ pT231 } & \multicolumn{3}{|c|}{ pT181 } & \multicolumn{3}{|c|}{ pT205 } & \multicolumn{2}{|c|}{ pT217 } & & \multicolumn{2}{|c|}{ pT231 } \\
\hline & & $\mathbf{F}$ & M & $\mathbf{F}$ & M & $\mathbf{F}$ & $\mathbf{N}$ & & $\mathbf{F}$ & M & & & $M$ & $\mathbf{F}$ & & M & $\mathbf{F}$ & M & & $\mathbf{F}$ & M \\
\hline \multirow{5}{*}{1} & Pretangle & & & & & & & & & & & & & & & & & & & & \\
\hline & Intermediary 1 & & & & & & & & & & & & & & & & & & & & \\
\hline & Mature Tangle & & & & & & & & & & & & & & & & & & & & \\
\hline & Intermediary 2 & & & & & & & & & & & & & & & & & & & & \\
\hline & Ghost Tangle & & & & & & & & & & & & & & & & & & & & \\
\hline \multirow{5}{*}{ ॥ } & Pretangle & & & & & & & & & & & & & & & & & & & & \\
\hline & Intermediary 1 & & & & & & & & & & & & & & & & & & & & \\
\hline & Mature Tangle & & & & & & & & & & & & & & & & & & & & \\
\hline & Intermediary 2 & & & & & & & & & & & & & & & & & & & & \\
\hline & Ghost Tangle & & & & & & & & & & & & & & & & & & & & \\
\hline \multirow{5}{*}{ III } & Pretangle & & & & & & & & & & & & & & & & & & & & \\
\hline & Intermediary 1 & & & & & & & & & & & & & & & & & & & & \\
\hline & Mature Tangle & & & & & & & & & & & & & & & & & & & & \\
\hline & Intermediary 2 & & & & & & & & & & & & & & & & & & & & \\
\hline & Ghost Tangle & & & & & & & & & & & & & & & & & & & & \\
\hline \multirow{5}{*}{ IV } & Pretangle & & & & & & & & & & & & & & & & & & & & \\
\hline & Intermediary 1 & & & & & & & & & & & & & & & & & & & & \\
\hline & Mature Tangle & & & & & & & & & & & & & & & & & & & & \\
\hline & Intermediary 2 & & & & & & & & & & & & & & & & & & & & \\
\hline & Ghost Tangle & & & & & & & & & & & & & & & & & & & & \\
\hline \multirow{5}{*}{$\mathrm{v}$} & Pretangle & & & & & & & & & & & & & & & & & & & & \\
\hline & Intermediary 1 & & & & & & & & & & & & & & & & & & & & \\
\hline & Mature Tangle & & & & & & & & & & & & & & & & & & & & \\
\hline & \begin{tabular}{|l|} 
Intermediary 2 \\
\end{tabular} & & & & & & & & & & & & & & & & & & & & \\
\hline & Ghost Tangle & & & & & & & & & & & & & & & & & & & & \\
\hline \multirow{5}{*}{$\mathrm{VI}$} & Pretangle & & & & & & & & & & & & & & & & & & & & \\
\hline & Intermediary 1 & & & & & & & & & & & & & & & & & & & & \\
\hline & Mature Tangle & & & & & & & & & & & & & & & & & & & & \\
\hline & Intermediary 2 & & & & & & & & & & & & & & & & & & & & \\
\hline & Ghost Tangle & & & & & & & & & & & & & & & & & & & & \\
\hline
\end{tabular}

pT181

b

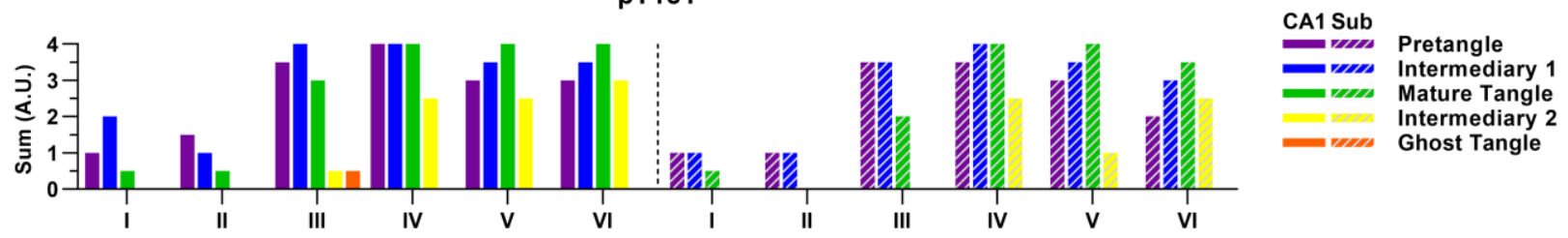

C

pT205

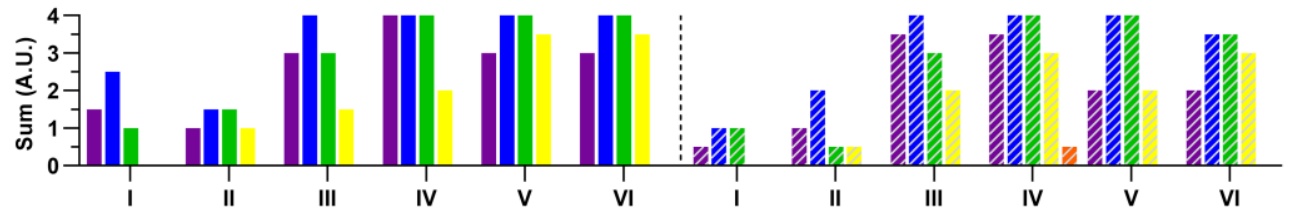

d

pT217

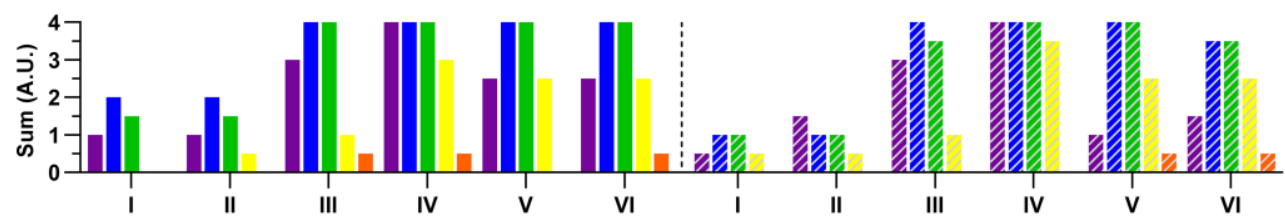

e

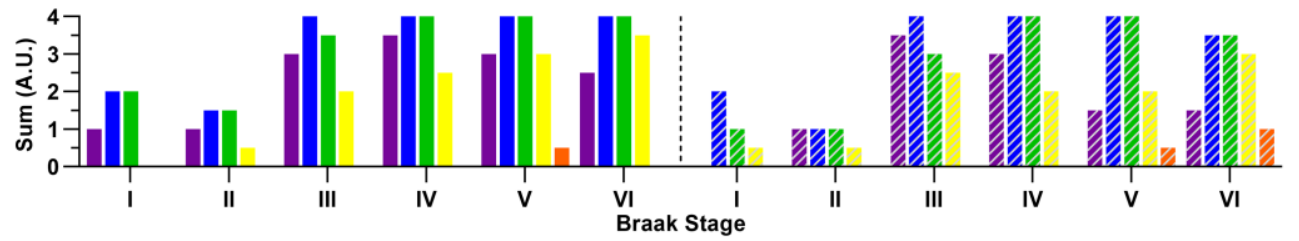

Figure 3. Semi-quantification of neurofibrillary tangle maturity levels for each phosphorylated tau site. a Heatmap visualizing semi-quantification from each case in the CA1 and subiculum. Observations are provided for each case stratified by Braak stage (major row) and phosphorylated tau site (major column). Sum of semiquantification (y-axis) plotted for the CA1 (left) and subiculum (right) for the b pT181, c pT205, d pT217, and e pT231 stained slides grouped by Braak stage (xaxis). Acronyms: F, female; M, male; Sub, subiculum; I1, intermediary 1; I2, intermediary 2; A.U.; arbitrary unit. 
bioRxiv preprint doi: https://doi.org/10.1101/2021.08.25.457363; this version posted August 26, 2021. The copyright holder for this preprint (which was not certified by peer review) is the author/funder, who has granted bioRxiv a license to display the preprint in perpetuity. It is made available under aCC-BY-NC 4.0 International license.

increase the brightness for illustration purposes. The heatmap was created in Microsoft Excel (Microsoft 365, version 16.0.13127.21336). Graphs were created using GraphPad Prism (version 9.0.0).

\section{Results}

Morphologic characteristics of neurofibrillary tangle and neuritic pathology

To evaluate the neurofibrillary tangle maturity level for each phosphorylated tau site, we performed immunohistochemistry on serial sections of the hippocampus for each antibody. At least one instance of each neurofibrillary tangle maturity level was visualized for all phosphorylated tau sites (Fig. 2). In addition, we found neuritic pathology (neuropil threads, neuritic plaques, and tangle associated neuritic clusters) was recognized by all phosphorylated tau antibodies (Fig. 2). Pathologic features of ARTAG (thorn shaped astrocytes) and argyrophilic grains disease (coiled bodies) were also observed (Supplementary Fig. 2). To determine the predominance of neurofibrillary tangle maturity level, we semi-quantified the presence or absence of pretangles, intermediary $1 \mathrm{~s}$, mature tangles, intermediary $2 \mathrm{~s}$, and ghost tangles (Fig. 3). There was a predilection towards earlier neurofibrillary tangle pathology especially in earlier Braak stages. Ghost tangles were extremely rare for all phosphorylated tau sites.

\section{Regional tau burden in CA1 and subiculum}

We sought to determine the regional differences of tau pathology recognized by these phosphorylated tau antibodies between the CA1 and subiculum. In the past, we observed nearly twice the number of neurofibrillary tangles in the subiculum compared to CA1 in the typical AD subtype, as visualized by thioflavin-S [43]. While tau burden in the subiculum compared to the CA1 was higher for all phosphorylated tau sites, this increase was attenuated compared to the thioflavin-S tangle counts (ratio of subiculum:CA1 for pT181=1.2 $\left[\mathrm{R}^{2}=0.896\right] ; \quad \mathrm{pT} 205=1.1$, $\left[\mathrm{R}^{2}=0.932\right] ;$ pT217=1.2 $\quad\left[\mathrm{R}^{2}=0.940\right] ;$ pT231 $=1.2 \quad\left[\mathrm{R}^{2}=0.901\right]$; thioflavin- $S=1.7\left[R^{2}=0.928\right]$ ) (Fig. 4). In the $C A 1$ and subiculum, we found no qualitative difference between the neurofibrillary tangle maturity levels visualized by each phosphorylated tau site. Notably, the frequency of pretangles in Braak stage V/VI were rarer in subiculum compared to the CA1 (Fig. 3).

\section{Global hippocampal evaluation of tau burden}

We next sought to determine differences between the phosphorylated tau sites when using the global tau measure, Braak stage $[12,13]$, to stratify cases. In Braak stages I and II, there were primarily rare pretangles and intermediary 1s (Fig. 3). By Braak stage III, there were frequent pretangles, intermediary $1 \mathrm{~s}$, and mature tangles, with rare intermediary 2 s (Fig. 3). From Braak stages IV to VI, there were frequent pretangles, intermediary $1 \mathrm{~s}$, mature tangles, and an increasing amount of intermediary $2 \mathrm{~s}$; however, there were relatively fewer pretangles in Braak stages $\mathrm{V}$ and VI (Fig. 3). Ghost tangles were absent to rare across all Braak stages.

In general, tau burden measurements were higher through each Braak stage (Fig. 5, 6). pT181 burden increased steadily between Braak stage III and Braak stage VI. pT205 burden increased from Braak stage II to VI, where burden appeared to level off between Braak stages IV and VI. pT217 burden increased from Braak stage II to III, sharply increased from Braak stages III to IV, leveled off from Braak stage IV to V, before increasing again to stage VI. Finally, pT231 burden increased more steadily between Braak stage III to VI.

\section{Discussion}

Our findings provide neurobiologic evidence that fluid-based phosphorylated tau biomarker sites in the proline-rich domain are present during earlier neurofibrillary tangle maturity. While all neurofibrillary tangle maturity levels were observed in pT181, pT205, pT217, and pT231, there was a predilection toward pretangles, intermediary $1 \mathrm{~s}$, and mature tangles. The striking difference in vulnerability between CA1 and subiculum tangle counts observed on thioflavin-S was not as readily observed in tau burden measurements of the phosphorylated tau sites suggesting diminished antibody recognition once tangle pathology matured to advanced levels. Phosphorylated tau burden generally increased as Braak stage increased with some plateauing observed in later Braak stages.

While the temporal sequence of detectable phosphorylated tau levels in fluids is still under investigation [4, 7,39 ], evidence suggests that fluid tau levels may elevate earlier than observed uptake on tau positron emission tomography (PET) [23]. Previous tau PET autoradiographic studies suggested that flortaucipir (AV-1451) may recognize middling to advanced neurofibrillary tangle maturity levels $[30,35]$. However, there is a lack of in-depth characterization of the neurofibrillary tangle maturity levels [42] recognized by the phosphorylated tau fluid biomarker sites. To fill this knowledge gap, we performed deep phenotyping of neurofibrillary tangle morphology recognized by pT181, pT205, pT217, and pT231 and employed digital pathology to quantify tau burden. We found that all phosphorylated tau sites studied are present primarily in earlier neurofibrillary tangle maturity levels. Their recognition of pretangles, intermediary $1 \mathrm{~s}$, and mature tangles may help explain why these biomarker sites are observed earlier during the $\mathrm{AD}$ dementia course $[4,8,21,37]$.

To put in context of the current study, and our morphologic characterization across neurofibrillary tangle maturity, we retrospectively examined photomicrographs from previous studies utilizing antibodies that recognized these phosphorylated tau sites. Evaluation of these photomicrographs support our results that pT181 [5, 48], pT205 [50, 51, 54, 60], pT217 [18], and pT231 [5, 10, 22, 32, 34, 58] recognize earlier neurofibrillary tangle maturity levels as we observed labeling of pretangles and mature tangles but not ghost tangles. Based on anticipated projected course in dominantly inherited $\mathrm{AD}$ cases, some phosphorylated tau fluid biomarkers were temporally sequenced, suggesting that cerebrospinal fluid levels of p-tau217 may elevate earlier, followed by p-tau181, then p-tau205 [8]. pT231 was recently suggested to be one of the initial phosphorylated sites found in neurons that may develop earlier than pretangles [3], which supports evidence from a plasma study in an autopsy cohort showing plasma p-tau231 levels may distinguish Braak 0 from Braak I-II [4]. Although more work is needed to disentangle the temporal sequence of phosphorylation events, we provide histopathologic evidence that pT181, pT205, pT217, and pT231 are expressed early in the neurofibrillary tangle lifespan. Moreover, accumulation of phosphorylated tau pathology recognizing the proline-rich domain was observed prior to the accumulation of amyloid plaques in three individuals with a Thal amyloid phase 0 (Case \#2,\#8,\#11). 
bioRxiv preprint doi: https://doi.org/10.1101/2021.08.25.457363; this version posted August 26, 2021. The copyright holder for this preprint (which was not certified by peer review) is the author/funder, who has granted bioRxiv a license to display the preprint in perpetuity. It is made available under aCC-BY-NC 4.0 International license.
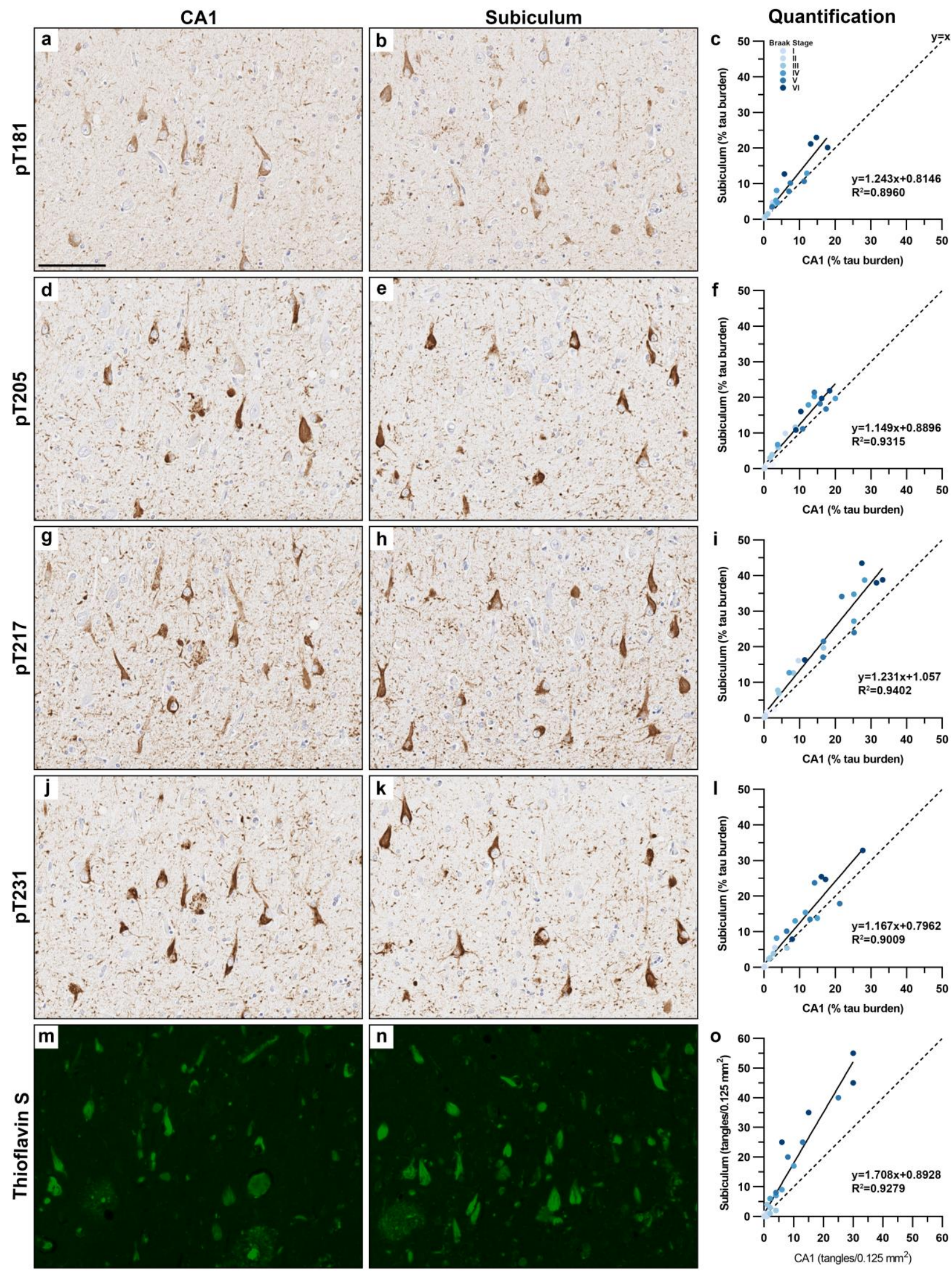

Figure 4. Neurofibrillary tangle pathology in the CA1 and subiculum. Representative images from pT181 in the a CA1 and b subiculum with $\mathbf{c}$ quantification. Representative images from pT205 in the $\mathbf{d ~ C A 1}$ and e subiculum with $\mathbf{f}$ quantification. Representative images from pT217 in the $\mathbf{g}$ CA1 and $\mathbf{h}$ subiculum with $\mathbf{i}$ quantification. Representative images from pT231 in the $\mathbf{j}$ CA1 and $\mathbf{k}$ subiculum with $\mathbf{l}$ quantification. Representative images from Thioflavin S in the $\mathbf{m}$ CA1 and $\mathbf{n}$ subiculum with $\mathbf{o}$ quantification. Tau burden measurements were plotted to evaluate severity differences between the CA1 and subiculum, where the slope of the line $(\mathrm{m})$ provides the subiculum:CA1 ratio from the slope intercept form of a straight line $(\mathrm{y}=\mathrm{mx}+\mathrm{b})$. A slope of 1 would indicate even distribution (dotted line) and a slope of 2 would be indicative of twice the amount of pathology in subiculum compared to CA1. Tau burden in the subiculum was higher than CA1 for each of the phosphorylated tau sites examined, but differences did not reach the nearly doubled tangle density observed on thioflavin-S. Images are from case 18 . Dotted line represents the line of equality $(\mathrm{y}=\mathrm{x})$. Scale bar measures $100 \mu \mathrm{m}$. 
bioRxiv preprint doi: https://doi.org/10.1101/2021.08.25.457363; this version posted August 26, 2021. The copyright holder for this preprint (which was not certified by peer review) is the author/funder, who has granted bioRxiv a license to display the preprint in perpetuity. It is made available under aCC-BY-NC 4.0 International license.

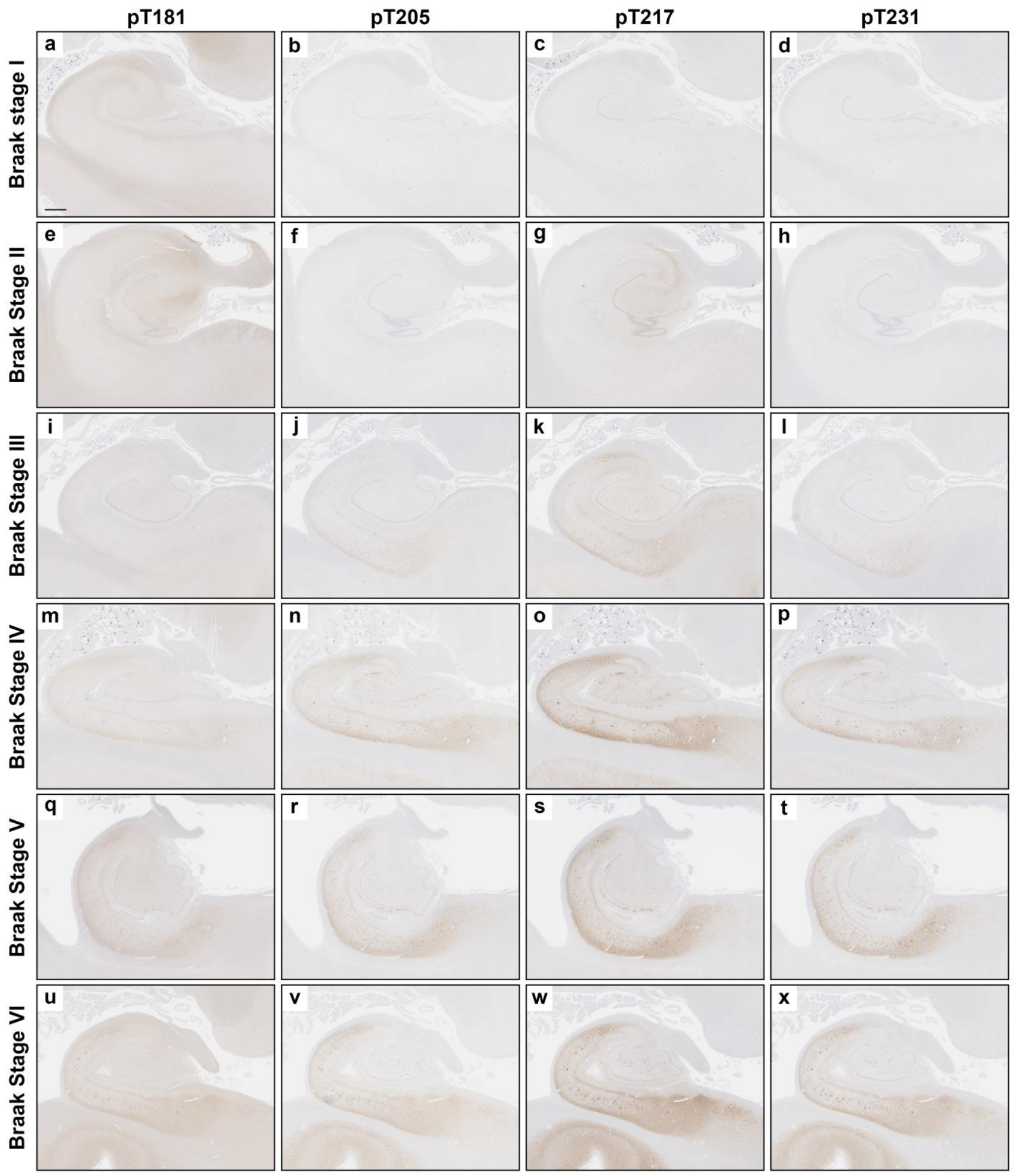

Figure 5. Phosphorylated tau expression generally increases through each Braak Stage. Representative images of immunohistochemistry of the whole posterior hippocampus from a-d Braak stage I (case 1), e-h Braak stage II (case 5), i-I Braak stage III (case 12), m-p Braak stage IV (case 13), q-t Braak stage V (case 19), and $\mathbf{u}-\mathbf{x}$ Braak stage VI (case 22). Serial sections were stained for $\mathbf{a}, \mathbf{e}, \mathbf{i}, \mathbf{m}, \mathbf{q}$, and $\mathbf{u}$ pT181; $\mathbf{b}, \mathbf{f}, \mathbf{j}, \mathbf{n}, \mathbf{r}$, and $\mathbf{v}$ pT205; $, \mathbf{c}, \mathbf{k}, \mathbf{o}, \mathbf{s}$, and $\mathbf{w}$ pT217; and d, h, l, p, t, and $\mathbf{x}$ pT231. As expected, with each increasing Braak stage the hippocampal size decreased. Immunohistochemical staining of tau was visibly increased with each increasing Braak stage. 


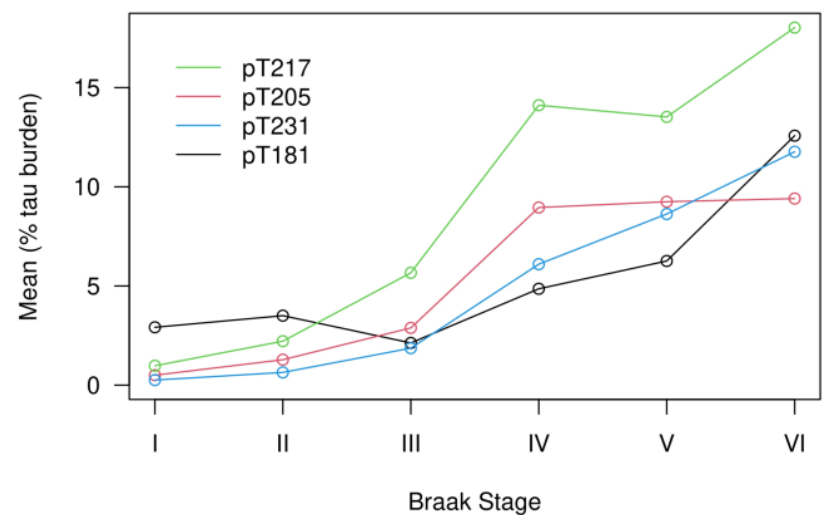

Figure 6. Phosphorylated tau increases through each Braak stage. When comparing tau burden measured across cases at each Braak stages, pT181 burden increased steadily between Braak stage III and Braak stage VI. pT205 burden increased from Braak stage II to VI and appeared to level off between Braak stages IV and VI. pT217 burden increased from Braak stage II to III, and then sharply increased from Braak stages III to IV. pT217 burden leveled off from Braak stage IV to V, before increasing again in stage VI. Finally, pT231 burden increased more steadily between Braak stage III to VI. Line graphs plotted the fitted means using positive pixel count burden for each Braak stage.

To further investigate differences in regional vulnerability, we elected to examine the CA1 and subiculum, two hippocampal subsectors known to be vulnerable in AD. Based upon observations of nearly twice the number of thioflavin-S positive tangles in the subiculum compared to the CA1 in typical $\mathrm{AD}[43,46]$, our goal was to investigate differences in phosphorylated tau burden in these two regions. However, while phosphorylated tau burden was increased in subiculum compared to CA1, this effect was attenuated compared to thioflavin-S positive tangle counts. We speculate this attenuation may be due to the recognition of pretangles and intermediate $1 \mathrm{~s}$ by phosphorylated tau sites, which may decrease in number as the disease continues and tau fibrils form into $\beta$-pleated sheet structures readily recognized by thioflavin-S. The current study employed digital pathology to quantify phosphorylated tau burden. Thus, we cannot rule out the contribution of neuritic pathology measured by burden analyses not captured by tangle counts performed on thioflavin-S. It is unclear why the subiculum has 1.5-2 times the amount of neurofibrillary tangle burden compared to the CA1 [43, 46]. As the subiculum is the major outflow pathway of the hippocampus that receives multiple connections from CA1 and entorhinal cortex [36], these anatomical differences may confer heightened vulnerability to advanced neurofibrillary tangle maturity. Evaluation in the context of reciprocal connections [29] or perhaps populations of excitatory neurons [27] may warrant future investigation.

We further investigated hippocampal differences in these phosphorylated tau sites across a global measure of tau distribution, Braak stage $[12,13]$. As expected in Braak stages III, we found minimal neurofibrillary tangle pathology primarily consisting of pretangles, intermediary $1 \mathrm{~s}$, and rarely mature tangles. However, by Braak stage III and onwards, there was an increase in the neurofibrillary tangle pathology with an increase in mature tangle and rare observations of intermediary 2. By Braak stage $\mathrm{V}$, there was a notable decrease in pretangle population. This is not unexpected as the number of unaffected neurons with potential to accumulate pathology decreases as pathology burden increases [16]. Ghost tangles were not commonly observed, which may indicate the loss of the phosphate group at the advanced maturity levels. We hypothesize this is because as ghost tangles are the remnants of mature tangles once the neuron has died [2, 49] they are no longer contained by a membrane and as such are exposed to the surrounding environment including phosphatases. In a neuropathologically diagnosed cohort, plasma p-tau181 and p-tau231 levels were found to increase with Braak stage [4] and suggested to plateau in very advanced stages of disease [26]. Our findings provide support of the observed plateauing, suggesting that as the shift from early to advanced tangle maturity occurs recognition by these phosphorylated tau sites in the proline-rich domain may be diminished.

Our study is not without limitations. One such is sample size; while $n=4$ cases per Braak stage is adequate for the morphology characterization and semiquantitative methods of neurofibrillary tangle maturity, larger sample sizes are necessary to evaluate and interpret tau burden differences between Braak stages. Another limitation concerns the thickness of tissue sections. It is difficult to be certain of intermediary 2 tangles, as it is possible that the nucleus is out of plane of section. To overcome this, thicker sections can be used to include the entire neurofibrillary tangle. In the current study, we observed lighter staining by the pT181 antibody compared to the other phosphorylated tau sites. As antibody affinity may affect immunohistochemical burden analyses, caution is warranted in interpretation of which phosphorylated tau site is increased the earliest in the current study. Additionally, we chose to focus on the hippocampus as this region is well-characterized in terms of neurofibrillary tangle maturity [6, 42, 55]. As neurofibrillary tangle maturity is not well-characterized in cortical regions, future studies should consider characterizing neurofibrillary tangle maturity levels in these regions to facilitate investigation of these phosphorylated tau fluid biomarker sites.

In conclusion, we performed a deep postmortem characterization of four phosphorylated tau fluid biomarker sites (pT181, pT205, pT217, and pT231) that are reliably elevated in AD dementia. To our knowledge, this is the first time these four phosphorylated tau sites are characterized together in the postmortem brain to evaluate recognition of neurofibrillary tangle maturity. While all neurofibrillary tangle maturity levels were visualized by each of the four phosphorylated tau sites, we observed a predilection towards earlier neurofibrillary tangle maturity with extremely rare observations of ghost tangles. Although fluid biomarkers do not provide regional involvement captured by tau PET imaging, our study demonstrates these phosphorylated tau sites in the proline-rich domain readily recognize early aspects of tangle maturity and may provide keen insight into the initial phase of neurofibrillary tangle changes.

\section{Acknowledgements}

We are grateful to Virginia Phillips, Ariston Librero, Jo Landino, Jessica Tranovich, Janisse Cabrera, and the Cytometry and Imaging Lab for histologic and imaging support.

\section{Compliance with Ethical Standards}

\section{Funding}

The investigators are supported by grants from National Institute on Aging (R01 AG054449, P30 AG062677, RF1 AG069052, U01 AG057195, and P50 AG047266) and the Florida Department of 
bioRxiv preprint doi: https://doi.org/10.1101/2021.08.25.457363; this version posted August 26, 2021. The copyright holder for this preprint (which was not certified by peer review) is the author/funder, who has granted bioRxiv a license to display the preprint in perpetuity. It is made available under aCC-BY-NC 4.0 International license.

Health, Ed and Ethel Moore Alzheimer's Disease Research Program (8AZ06, 20A22).

\section{Potential conflicts of interest}

CMM, SAL, JEC, HS, CL, MC-C, RD, and DWD have no conflicts of interest to declare. RCP is a consultant for Biogen, Inc., Roche, Inc., Merck, Inc., Genentech Inc. (DSMB) and Eisai, Inc., receives publishing royalties from Mild Cognitive Impairment (Oxford University Press, 2003), UpToDate. NRG-R takes part in multicentre trials supported by AbbVie, Eli Lilly, and Biogen, outside the submitted work. MMM has consulted for Biogen and Brain Protection Company and receives funding from the NIH/NIA and DOD. MEM served as a consultant for AVID Radiopharmaceuticals.

\section{Declarations}

All brains were acquired with appropriate ethical approval, and the research performed on postmortem samples was approved by the Mayo Clinic Research Executive Committee.

\begin{tabular}{ll}
\multicolumn{2}{l}{ Abbreviations } \\
AD & Alzheimer's disease \\
ARTAG & Aging-related tau astrogliopathy \\
CA & Cornu ammonis \\
FLAME & Florida Autopsied Multi-Ethnic \\
I1 & Intermediary 1 \\
I2 & Intermediary 2 \\
p & Phosphorylation \\
PA & Pathological aging \\
PART & Primary age related tauopathy \\
PET & Positron emission tomography \\
SC & Senile change \\
T & Threonine \\
TSA & Thorn shaped astrocytes \\
VaD & Vascular disease
\end{tabular}

\section{References}

1 Alzheimer A (1911) Über eigenartige Krankheitsfälle des späteren Alters. Z Gesamte Neurol Psy 4:356-385. https://doi.org/10.1007/bf02866241

2 Alzheimer A (1907) Über eine eigenartige Erkankung der Hirnrinde. Allg Z Psychiatr Ps 18:177-179.

3 Aragão Gomes L, Uytterhoeven V, Lopez-Sanmartin D, Tomé SO, Tousseyn $\mathrm{T}$, Vandenberghe R, Vandenbulcke M, von Arnim CAF, Verstreken P, Thal DR (2021) Maturation of neuronal AD-tau pathology involves site-specific phosphorylation of cytoplasmic and synaptic tau preceding conformational change and fibril formation. Acta Neuropathol 141:173-192. https://doi.org/10.1007/s00401-020-02251-6

4 Ashton NJ, Pascoal TA, Karikari TK, Benedet AL, Lantero-Rodriguez J, Brinkmalm G, Snellman A, Schöll M, Troakes C, Hye A, Gauthier S, Vanmechelen E, Zetterberg H, Rosa-Neto P, Blennow K (2021) Plasma ptau231: a new biomarker for incipient Alzheimer's disease pathology. Acta Neuropathol 141:709-724. https://doi.org/10.1007/s00401-021-02275-6

5 Augustinack JC, Schneider A, Mandelkow EM, Hyman BT (2002) Specific tau phosphorylation sites correlate with severity of neuronal cytopathology in Alzheimer's disease. Acta Neuropathol 103:26-35. https://doi.org/10.1007/s004010100423

6 Bancher C, Brunner C, Lassmann H, Budka H, Jellinger K, Wiche G, Seitelberger F, Grundke-Iqbal I, Iqbal K, Wisniewski HM (1989) Accumulation of abnormally phosphorylated tau precedes the formation of neurofibrillary tangles in Alzheimer's disease. Brain Res 477:90-99. https://doi.org/10.1016/0006-8993(89)91396-6

7 Barthélemy NR, Bateman RJ, Marin P, Becher F, Sato C, Lehmann S, Gabelle A (2017) Tau hyperphosphorylation on T217 in cerebrospinal fluid is specifically associated to amyloid- $\beta$ pathology. bioRxiv. https://doi.org/10.1101/226977

8 Barthélemy NR, Li Y, Joseph-Mathurin N, Gordon BA, Hassenstab J, Benzinger TLS, Buckles V, Fagan AM, Perrin RJ, Goate AM, Morris JC, Karch CM, Xiong C, Allegri R, Mendez PC, Berman SB, Ikeuchi T, Mori H,
Shimada H, Shoji M, Suzuki K, Noble J, Farlow M, Chhatwal J, GraffRadford NR, Salloway S, Schofield PR, Masters CL, Martins RN, O'Connor A, Fox NC, Levin J, Jucker M, Gabelle A, Lehmann S, Sato C, Bateman RJ, McDade E, the Dominantly Inherited Alzheimer Network (2020) A soluble phosphorylated tau signature links tau, amyloid and the evolution of stages of dominantly inherited Alzheimer's disease. Nat Med 26:398-407. https://doi.org/10.1038/s41591-020-0781-z

9 Barthélemy NR, Mallipeddi N, Moiseyev P, Sato C, Bateman RJ (2019) Tau Phosphorylation Rates Measured by Mass Spectrometry Differ in the Intracellular Brain vs. Extracellular Cerebrospinal Fluid Compartments and Are Differentially Affected by Alzheimer's Disease. Front Aging Neurosci 11:121. https://doi.org/10.3389/fnagi.2019.00121

10 Bengoa-Vergniory N, Velentza-Almpani E, Silva AM, Scott C, VargasCaballero M, Sastre M, Wade-Martins R, Alegre-Abarrategui J (2021) Tauproximity ligation assay reveals extensive previously undetected pathology prior to neurofibrillary tangles in preclinical Alzheimer's disease. Acta Neuropathol Commun 9:18. https://doi.org/10.1186/s40478-020-01117-y

11 Blennow K, Wallin A, Ågren H, Spenger C, Siegfried J, Vanmechelen E (1995) Tau protein in cerebrospinal fluid: a biochemical marker for axonal degeneration in Alzheimer disease? Mol Chem Neuropathol 26:231-245. https://doi.org/10.1007/BF02815140

12 Braak H, Alafuzoff I, Arzberger T, Kretzschmar H, Del Tredici K (2006) Staging of Alzheimer disease-associated neurofibrillary pathology using paraffin sections and immunocytochemistry. Acta Neuropathol 112:389-404. https://doi.org/10.1007/s00401-006-0127-z

13 Braak H, Braak E (1991) Neuropathological stageing of Alzheimer-related changes. Acta Neuropathol 82:239-259. https://doi.org/10.1007/BF00308809

14 Crary JF, Trojanowski JQ, Schneider JA, Abisambra JF, Abner EL, Alafuzoff I, Arnold SE, Attems J, Beach TG, Bigio EH, Cairns NJ, Dickson DW, Gearing M, Grinberg LT, Hof PR, Hyman BT, Jellinger K, Jicha GA, Kovacs GG, Knopman DS, Kofler J, Kukull WA, Mackenzie IR, Masliah E, McKee A, Montine TJ, Murray ME, Neltner JH, Santa-Maria I, Seeley WW, SerranoPozo A, Shelanski ML, Stein T, Takao M, Thal DR, Toledo JB, Troncoso JC, Vonsattel JP, White CL, 3rd, Wisniewski T, Woltjer RL, Yamada M, Nelson PT (2014) Primary age-related tauopathy (PART): a common pathology associated with human aging. Acta Neuropathol 128:755-766. https://doi.org/10.1007/s00401-014-1349-0

15 Dickson DW, Crystal HA, Mattiace LA, Masur DM, Blau AD, Davies P, Yen S-H, Aronson MK (1992) Identification of normal and pathological aging in prospectively studied nondemented elderly humans. Neurobiol Aging 13:179189. https://doi.org/10.1016/0197-4580(92)90027-U

16 Fukutani Y, Kobayashi K, Nakamura I, Watanabe K, Isaki K, Cairns NJ (1995) Neurons, intracellular and extracellular neurofibrillary tangles in subdivisions of the hippocampal cortex in normal ageing and Alzheimer's disease. Neurosci Lett 200:57-60. https://doi.org/10.1016/03043940(95)12083-g

17 Goedert M, Jakes R, Crowther RA, Cohen P, Vanmechelen E, Vandermeeren M, Cras P (1994) Epitope mapping of monoclonal antibodies to the paired helical filaments of Alzheimer's disease: identification of phosphorylation sites in tau protein. Biochem J 301:871-877. https://doi.org/10.1042/bj3010871

18 Hanes J, Kovac A, Kvartsberg H, Kontsekova E, Fialova L, Katina S, Kovacech B, Stevens E, Hort J, Vyhnalek M, Boonkamp L, Novak M, Zetterberg H, Hansson O, Scheltens P, Blennow K, Teunissen CE, Zilka N (2020) Evaluation of a novel immunoassay to detect p-tau Thr217 in the CSF to distinguish Alzheimer disease from other dementias. Neurology 95:e3026e3035. https://doi.org/10.1212/WNL.0000000000010814

19 Horie K, Barthélemy NR, Sato C, Bateman RJ (2021) CSF tau microtubule binding region identifies tau tangle and clinical stages of Alzheimer's disease. Brain 144:515-527. https://doi.org/10.1093/brain/awaa373

20 Jack CR, Jr., Bennett DA, Blennow K, Carrillo MC, Dunn B, Haeberlein SB, Holtzman DM, Jagust W, Jessen F, Karlawish J, Liu E, Molinuevo JL, Montine T, Phelps C, Rankin KP, Rowe CC, Scheltens P, Siemers E, Snyder HM, Sperling R, Contributors (2018) NIA-AA Research Framework: Toward a biological definition of Alzheimer's disease. Alzheimers Dement 14:535562. https://doi.org/10.1016/j.jalz.2018.02.018

21 Janelidze S, Mattsson N, Palmqvist S, Smith R, Beach TG, Serrano GE, Chai $\mathrm{X}$, Proctor NK, Eichenlaub U, Zetterberg H, Blennow K, Reiman EM, Stomrud E, Dage JL, Hansson O (2020) Plasma P-tau181 in Alzheimer's disease: relationship to other biomarkers, differential diagnosis, neuropathology and longitudinal progression to Alzheimer's dementia. Nat Med 26:379-386. https://doi.org/10.1038/s41591-020-0755-1

22 Jicha GA, Lane E, Vincent I, Otvos L, Jr., Hoffmann R, Davies P (1997) A conformation- and phosphorylation-dependent antibody recognizing the 
bioRxiv preprint doi: https://doi.org/10.1101/2021.08.25.457363; this version posted August 26, 2021. The copyright holder for this preprint (which was not certified by peer review) is the author/funder, who has granted bioRxiv a license to display the preprint in perpetuity. It is made available under aCC-BY-NC 4.0 International license.

paired helical filaments of Alzheimer's disease. J Neurochem 69:2087-2095. https://doi.org/10.1046/j.1471-4159.1997.69052087.x

23 Karikari TK, Pascoal TA, Ashton NJ, Janelidze S, Benedet AL, Rodriguez JL, Chamoun M, Savard M, Kang MS, Therriault J, Schöll M, Massarweh G, Soucy JP, Höglund K, Brinkmalm G, Mattsson N, Palmqvist S, Gauthier S, Stomrud E, Zetterberg H, Hansson O, Rosa-Neto P, Blennow K (2020) Blood phosphorylated tau 181 as a biomarker for Alzheimer's disease: a diagnostic performance and prediction modelling study using data from four prospective cohorts. Lancet Neurol 19:422-433. https://doi.org/10.1016/S14744422(20)30071-5

24 Kohnken R, Buerger K, Zinkowski R, Miller C, Kerkman D, DeBernardis J, Shen J, Möller H-J, Davies P, Hampel H (2000) Detection of tau phosphorylated at threonine 231 in cerebrospinal fluid of Alzheimer's disease patients. Neurosci Lett 287:187-190. https://doi.org/10.1016/s03043940(00)01178-2

25 Kovacs GG, Ferrer I, Grinberg LT, Alafuzoff I, Attems J, Budka H, Cairns NJ, Crary JF, Duyckaerts C, Ghetti B, Halliday GM, Ironside JW, Love S, Mackenzie IR, Munoz DG, Murray ME, Nelson PT, Takahashi H, Trojanowski JQ, Ansorge O, Arzberger T, Baborie A, Beach TG, Bieniek KF, Bigio EH, Bodi I, Dugger BN, Feany M, Gelpi E, Gentleman SM, Giaccone G, Hatanpaa KJ, Heale R, Hof PR, Hofer M, Hortobagyi T, Jellinger K, Jicha GA, Ince P, Kofler J, Kovari E, Kril JJ, Mann DM, Matej R, McKee AC, McLean C, Milenkovic I, Montine TJ, Murayama S, Lee EB, Rahimi J, Rodriguez RD, Rozemuller A, Schneider JA, Schultz C, Seeley W, Seilhean D, Smith C, Tagliavini F, Takao M, Thal DR, Toledo JB, Tolnay M, Troncoso JC, Vinters HV, Weis S, Wharton SB, White CL, 3rd, Wisniewski T, Woulfe JM, Yamada M, Dickson DW (2016) Aging-related tau astrogliopathy (ARTAG): harmonized evaluation strategy. Acta Neuropathol 131:87-102. https://doi.org/10.1007/s00401-015-1509-x

26 Lantero Rodriguez J, Karikari TK, Suárez-Calvet M, Troakes C, King A, Emersic A, Aarsland D, Hye A, Zetterberg H, Blennow K, Ashton NJ (2020) Plasma p-tau181 accurately predicts Alzheimer's disease pathology at least 8 years prior to post-mortem and improves the clinical characterisation of cognitive decline. Acta Neuropathol 140:267-278. https://doi.org/10.1007/s00401-020-02195-x

27 Leng K, Li E, Eser R, Piergies A, Sit R, Tan M, Neff N, Li SH, Rodriguez RD, Suemoto CK, Leite REP, Ehrenberg AJ, Pasqualucci CA, Seeley WW, Spina S, Heinsen H, Grinberg LT, Kampmann M (2021) Molecular characterization of selectively vulnerable neurons in Alzheimer's disease. Nat Neurosci 24:276-287. https://doi.org/10.1038/s41593-020-00764-7

28 Liesinger AM, Graff-Radford NR, Duara R, Carter RE, Hanna Al-Shaikh FS, Koga S, Hinkle KM, DiLello SK, Johnson MF, Aziz A, Ertekin-Taner N, Ross OA, Dickson DW, Murray ME (2018) Sex and age interact to determine clinicopathologic differences in Alzheimer's disease. Acta Neuropathol 136:873-885. https://doi.org/10.1007/s00401-018-1908-x

29 Llorens-Martín M, Blazquez-Llorca L, Benavides-Piccione R, Rabano A, Hernandez F, Avila J, DeFelipe J (2014) Selective alterations of neurons and circuits related to early memory loss in Alzheimer's disease. Front Neuroanat 8:38. https://doi.org/10.3389/fnana.2014.00038

30 Lowe VJ, Curran G, Fang P, Liesinger AM, Josephs KA, Parisi JE, Kantarci K, Boeve BF, Pandey MK, Bruinsma T, Knopman DS, Jones DT, Petrucelli L, Cook CN, Graff-Radford NR, Dickson DW, Petersen RC, Jack CR, Jr., Murray ME (2016) An autoradiographic evaluation of AV-1451 Tau PET in dementia. Acta Neuropathol Commun 4:58. https://doi.org/10.1186/s40478016-0315-6

31 Lowe VJ, Lundt ES, Albertson SM, Min HK, Fang P, Przybelski SA, Senjem ML, Schwarz CG, Kantarci K, Boeve B, Jones DT, Reichard RR, Tranovich JF, Hanna Al-Shaikh FS, Knopman DS, Jack CR, Jr., Dickson DW, Petersen RC, Murray ME (2020) Tau-positron emission tomography correlates with neuropathology findings. Alzheimers Dement 16:561-571. https://doi.org/10.1016/j.jalz.2019.09.079

32 Luna-Muñoz J, Chávez-Macías L, García-Sierra F, Mena R (2007) Earliest stages of tau conformational changes are related to the appearance of a sequence of specific phospho-dependent tau epitopes in Alzheimer's disease. J Alzheimers Dis 12:365-375. https://doi.org/10.3233/jad-2007-12410

33 Luna-Muñoz J, García-Sierra F, Falcón V, Menéndez I, Chavez-Macias L, Mena R (2005) Regional conformational change involving phosphorylation of tau protein at the Thr231, precedes the structural change detected by Alz-50 antibody in Alzheimer's disease. J Alzheimers Dis 8:29-41. https://doi.org/10.3233/jad-2005-8104

34 Luna-Muñoz J, Peralta-Ramirez J, Chávez-Macías L, Harrington CR, Wischik CM, Mena R (2008) Thiazin red as a neuropathological tool for the rapid diagnosis of Alzheimer's disease in tissue imprints. Acta Neuropathol 116:507-515. https://doi.org/10.1007/s00401-008-0431-x
35 Marquié M, Normandin MD, Vanderburg CR, Costantino IM, Bien EA, Rycyna LG, Klunk WE, Mathis CA, Ikonomovic MD, Debnath ML, Vasdev N, Dickerson BC, Gomperts SN, Growdon JH, Johnson KA, Frosch MP, Hyman BT, Gómez-Isla T (2015) Validating novel tau positron emission tomography tracer [F-18]-AV-1451 (T807) on postmortem brain tissue. Ann Neurol 78:787-800. https://doi.org/10.1002/ana.24517

36 Matsumoto N, Kitanishi T, Mizuseki K (2019) The subiculum: Unique hippocampal hub and more. Neurosci Res 143:1-12. https://doi.org/10.1016/j.neures.2018.08.002

37 Mattsson N, Zetterberg H, Janelidze S, Insel PS, Andreasson U, Stomrud E, Palmqvist S, Baker D, Tan Hehir CA, Jeromin A, Hanlon D, Song L, Shaw LM, Trojanowski JQ, Weiner MW, Hansson O, Blennow K (2016) Plasma tau in Alzheimer disease. Neurology 87:1827-1835. https://doi.org/10.1212/WNL.0000000000003246

38 Mehta PD, Thal L, Wisniewski HM, Grundke-Iqbal I, Iqbal K (1985) Paired Helical Filament Antigen in CSF. The Lancet 326. https://doi.org/10.1016/s0140-6736(85)90074-1

39 Mielke MM, Aakre JA, Algeciras-Schimnich A, Proctor NK, Machulda MM, Eichenlaub U, Knopman DS, Vemuri P, Graff-Radford J, Jack CR, Jr., Petersen RC, Dage JL (2021) Comparison of CSF phosphorylated tau 181 and 217 for cognitive decline. Alzheimers Dement. https://doi.org/10.1002/alz.12415

40 Mielke MM, Frank RD, Dage JL, Jeromin A, Ashton NJ, Blennow K, Karikari TK, Vanmechelen E, Zetterberg H, Algeciras-Schimnich A, Knopman DS, Lowe V, Bu G, Vemuri P, Graff-Radford J, Jack CR, Jr., Petersen RC (2021) Comparison of Plasma Phosphorylated Tau Species With Amyloid and Tau Positron Emission Tomography, Neurodegeneration, Vascular Pathology, and Cognitive Outcomes. JAMA Neurology. https://doi.org/10.1001/jamaneurol.2021.2293

41 Mielke MM, Hagen CE, Xu J, Chai X, Vemuri P, Lowe VJ, Airey DC, Knopman DS, Roberts RO, Machulda MM, Jack CR, Jr., Petersen RC, Dage JL (2018) Plasma phospho-tau181 increases with Alzheimer's disease clinical severity and is associated with tau- and amyloid-positron emission tomography. Alzheimers Dement

14:989-997. https://doi.org/10.1016/j.jalz.2018.02.013

42 Moloney CM, Lowe VJ, Murray ME (2021) Visualization of neurofibrillary tangle maturity in Alzheimer's disease: A clinicopathologic perspective for biomarker research. Alzheimers Dement. https://doi.org/10.1002/alz.12321

43 Murray ME, Graff-Radford NR, Ross OA, Petersen RC, Duara R, Dickson DW (2011) Neuropathologically defined subtypes of Alzheimer's disease with distinct clinical characteristics: a retrospective study. Lancet Neurol 10:785796. https://doi.org/10.1016/S1474-4422(11)70156-9

44 Ossenkoppele R, Schonhaut DR, Schöll M, Lockhart SN, Ayakta N, Baker SL, O'Neil JP, Janabi M, Lazaris A, Cantwell A, Vogel J, Santos M, Miller ZA, Bettcher BM, Vossel KA, Kramer JH, Gorno-Tempini ML, Miller BL, Jagust WJ, Rabinovici GD (2016) Tau PET patterns mirror clinical and neuroanatomical variability in Alzheimer's disease. Brain 139:1551-1567. https://doi.org/10.1093/brain/aww027

45 Palmqvist S, Janelidze S, Quiroz YT, Zetterberg H, Lopera F, Stomrud E, Su Y, Chen Y, Serrano GE, Leuzy A, Mattsson-Carlgren N, Strandberg O, Smith R, Villegas A, Sepulveda-Falla D, Chai X, Proctor NK, Beach TG, Blennow K, Dage JL, Reiman EM, Hansson O (2020) Discriminative Accuracy of Plasma Phospho-tau217 for Alzheimer Disease vs Other Neurodegenerative Disorders. JAMA 324:772-781. https://doi.org/10.1001/jama.2020.12134

46 Petersen C, Nolan AL, de Paula França Resende E, Miller Z, Ehrenberg AJ, Gorno-Tempini ML, Rosen HJ, Kramer JH, Spina S, Rabinovici GD, Miller BL, Seeley WW, Heinsen H, Grinberg LT (2019) Alzheimer's disease clinical variants show distinct regional patterns of neurofibrillary tangle accumulation. Acta Neuropathol 138:597-612. https://doi.org/10.1007/s00401-019-02036-6

47 Santos OA, Pedraza O, Lucas JA, Duara R, Greig-Custo MT, Hanna AlShaikh FS, Liesinger AM, Bieniek KF, Hinkle KM, Lesser ER, Crook JE, Carrasquillo MM, Ross OA, Ertekin-Taner N, Graff-Radford NR, Dickson DW, Murray ME (2019) Ethnoracial differences in Alzheimer's disease from the FLorida Autopsied Multi-Ethnic (FLAME) cohort. Alzheimers Dement 15:635-643. https://doi.org/10.1016/j.jalz.2018.12.013

48 Scheper W, Hoozemans JJ (2015) The unfolded protein response in neurodegenerative diseases: a neuropathological perspective. Acta Neuropathol 130:315-331. https://doi.org/10.1007/s00401-015-1462-8

49 Stelzmann RA, Schnitzlein HN, Murtagh FR (1995) An English translation of Alzheimer's 1907 paper, "Uber eine eigenartige Erkankung der Hirnrinde". Clin Anat 8:429-431. https://doi.org/10.1002/ca.980080612

50 Strang KH, Goodwin MS, Riffe C, Moore BD, Chakrabarty P, Levites Y, Golde TE, Giasson BI (2017) Generation and characterization of new monoclonal antibodies targeting the PHF1 and AT8 epitopes on human tau. 
bioRxiv preprint doi: https://doi.org/10.1101/2021.08.25.457363; this version posted August 26, 2021. The copyright holder for this preprint (which was not certified by peer review) is the author/funder, who has granted bioRxiv a license to display the preprint in perpetuity. It is made available under aCC-BY-NC 4.0 International license.

Acta Neuropathol Commun 5:58. https://doi.org/10.1186/s40478-017-04580

51 Strang KH, Sorrentino ZA, Riffe CJ, Gorion KM, Vijayaraghavan N, Golde TE, Giasson BI (2019) Phosphorylation of serine 305 in tau inhibits aggregation. Neurosci $\quad$ Lett https://doi.org/10.1016/j.neulet.2018.11.011

52 Tatebe H, Kasai T, Ohmichi T, Kishi Y, Kakeya T, Waragai M, Kondo M, Allsop D, Tokuda T (2017) Quantification of plasma phosphorylated tau to use as a biomarker for brain Alzheimer pathology: pilot case-control studies including patients with Alzheimer's disease and down syndrome. Mol Neurodegener 12:63. https://doi.org/10.1186/s13024-017-0206-8

53 Thal DR, Rüb U, Orantes M, Braak H (2002) Phases of A beta-deposition in the human brain and its relevance for the development of AD. Neurology 58:1791-1800. https://doi.org/10.1212/wnl.58.12.1791

54 Trejo-Lopez JA, Sorrentino ZA, Riffe CJ, Prokop S, Dickson DW, Yachnis AT, Giasson BI (2020) Generation and Characterization of Novel Monoclonal Antibodies Targeting p62/sequestosome-1 Across Human Neurodegenerative Diseases. J Neuropathol Exp Neurol 79:407-418. https://doi.org/10.1093/jnen/nlaa007

55 Uchihara T (2014) Pretangles and neurofibrillary changes: similarities and differences between $\mathrm{AD}$ and $\mathrm{CBD}$ based on molecular and morphological evolution. Neuropathology 34:571-577. https://doi.org/10.1111/neup.12108

56 Vandermeeren M, Mercken M, Vanmechelen E, Six J, van de Voorde A, Martin JJ, Cras P (1993) Detection of tau proteins in normal and Alzheimer's disease cerebrospinal fluid with a sensitive sandwich enzyme-linked immunosorbent assay. J Neurochem 61:1828-1834. https://doi.org/10.1111/j.1471-4159.1993.tb09823.x

57 Vanmechelen E, Vanderstichele H, Davidsson P, Van Kerschaver E, Van Der Perre B, Sjögren M, Andreasen N, Blennow K (2000) Quantification of tau phosphorylated at threonine 181 in human cerebrospinal fluid: a sandwich ELISA with a synthetic phosphopeptide for standardization. Neurosci Lett 285:49-52. https://doi.org/10.1016/s0304-3940(00)01036-3

58 Vincent I, Rosado M, Davies P (1996) Mitotic mechanisms in Alzheimer's disease? J Cell Biol 132:413-425. https://doi.org/10.1083/jcb.132.3.413

59 Wolozin B, Davies P (1987) Alzheimer-related neuronal protein A68: specificity and distribution. Ann Neurol 22:521-526. https://doi.org/10.1002/ana.410220412

60 Xia Y, Prokop S, Gorion KM, Kim JD, Sorrentino ZA, Bell BM, Manaois AN, Chakrabarty P, Davies P, Giasson BI (2020) Tau Ser208 phosphorylation promotes aggregation and reveals neuropathologic diversity in Alzheimer's disease and other tauopathies. Acta Neuropathol Commun 8:88. https://doi.org/10.1186/s40478-020-00967-w 
bioRxiv preprint doi: https://doi.org/10.1101/2021.08.25.457363; this version posted August 26, 2021. The copyright holder for this preprint (which was not certified by peer review) is the author/funder, who has granted bioRxiv a license to display the preprint in perpetuity. It is made available under aCC-BY-NC 4.0 International license.

\section{Supplementary Information}

Supplementary Table 1. Case demographics

\begin{tabular}{|c|c|c|c|c|c|c|c|}
\hline Case & Sex & Age & Ethnoracial & $\begin{array}{l}A P O E \\
\varepsilon 4\end{array}$ & $\begin{array}{l}\text { Braak } \\
\text { Stage }\end{array}$ & Thal Phase & Pathologic Diagnosis \\
\hline 1 & $\mathrm{~F}$ & 85 & Hispanic & $\varepsilon 4-$ & $\mathrm{I}$ & 2 & PART, possible \\
\hline 2 & $\mathrm{~F}$ & 92 & White & $\varepsilon 4-$ & I & 0 & PART, definite \\
\hline 3 & $\mathrm{M}$ & 78 & White & $\varepsilon 4-$ & $\mathrm{I}$ & 2 & PART, possible/VaD \\
\hline 4 & $\mathrm{M}$ & 88 & White & $\varepsilon 4-$ & $\mathrm{I}$ & 1 & PART, possible/VaD \\
\hline 5 & $\mathrm{~F}$ & 81 & White & $\varepsilon 4-$ & II & 5 & PA \\
\hline 6 & $\mathrm{~F}$ & 78 & White & $\varepsilon 4-$ & II & 1 & PART, possible/VaD \\
\hline 7 & $\mathrm{M}$ & 83 & White & $\varepsilon 4-$ & II & 4 & $\mathrm{PA} / \mathrm{VaD}$ \\
\hline 8 & $\mathrm{M}$ & 70 & White & $\varepsilon 4-$ & II & 0 & PART, definite \\
\hline 9 & $\mathrm{~F}$ & 87 & White & $\varepsilon 4-$ & III & 3 & PA \\
\hline 10 & $\mathrm{~F}$ & 89 & White & $\varepsilon 4-$ & III & 3 & SC/VaD/ARTAG \\
\hline 11 & $\mathrm{M}$ & 88 & Hispanic & $\varepsilon 4-$ & III & 0 & PART, definite/VaD \\
\hline 12 & $\mathrm{M}$ & 93 & Black & $\varepsilon 4-$ & III & 2 & PART, possible \\
\hline 13 & $\mathrm{~F}$ & 82 & White & $\varepsilon 4+$ & IV & 5 & AD, early \\
\hline 14 & $\mathrm{~F}$ & 93 & White & $\varepsilon 4-$ & IV & 5 & $\mathrm{AD}$, early/VaD \\
\hline 15 & $\mathrm{M}$ & 84 & White & $\varepsilon 4-$ & IV & 3 & $\mathrm{AD}$, early/VaD \\
\hline 16 & $\mathrm{M}$ & 83 & White & $\varepsilon 4+$ & IV & 5 & $\mathrm{AD}$, early/VaD \\
\hline 17 & $\mathrm{~F}$ & 87 & White & $\varepsilon 4+$ & $\mathrm{V}$ & 5 & $\mathrm{AD}$ \\
\hline 18 & $\mathrm{~F}$ & 90 & Hispanic & $\varepsilon 4-$ & $\mathrm{V}$ & 5 & $\mathrm{AD}$ \\
\hline 19 & $\mathrm{M}$ & 82 & Hispanic & $\varepsilon 4+$ & $\mathrm{V}$ & 5 & $\mathrm{AD} / \mathrm{VaD}$ \\
\hline 20 & $\mathrm{M}$ & 84 & White & $\varepsilon 4+$ & $\mathrm{V}$ & 4 & $\mathrm{AD} / \mathrm{VaD}$ \\
\hline 21 & $\mathrm{~F}$ & 84 & White & $\varepsilon 4-$ & VI & 5 & $\mathrm{AD} / \mathrm{VaD}$ \\
\hline 22 & $\mathrm{~F}$ & 82 & White & $\varepsilon 4-$ & VI & 5 & $\mathrm{AD} / \mathrm{VaD}$ \\
\hline 23 & $\mathrm{M}$ & 71 & Hispanic & $\varepsilon 4+$ & VI & 5 & $\mathrm{AD}$ \\
\hline 24 & $\mathrm{M}$ & 75 & White & $\varepsilon 4+$ & VI & 5 & $\mathrm{AD}$ \\
\hline
\end{tabular}

AD, Alzheimer's disease; ARTAG, aging related tau astrogliopathy; PA, pathological aging; PART, primary age related tauopathy; $\mathrm{SC}$, senile change; $\mathrm{VaD}$, vascular disease 
Supplementary Table 2. Positive pixel count macro specifications for pT181, pT205, pT217, and pT231 stained sections.

\begin{tabular}{|l|l|}
\hline Algorithm & Positive Pixel Count \\
\hline Version & 9.1 \\
\hline View Width & 1000 \\
\hline View Height & 1000 \\
\hline Overlap Size & 0 \\
\hline Image Zoom & 1. \\
\hline Classifier & None \\
\hline Class List & \\
\hline Classifier Neighborhood & 0 \\
\hline Pixel Area (millimeter-squared) & $2.52506 \mathrm{e}-007$ \\
\hline Hue Value (Center) & 0.1 \\
\hline Hue Width & 0.1 \\
\hline Color Saturation Threshold & $8 . \mathrm{e}-002$ \\
\hline Intensity Threshold WEAK (Upper Limit) & 235 \\
\hline Intensity Threshold WEAK (Lower Limit) & 235 \\
\hline Intensity Threshold MEDIUM (Upper Limit) & 235 \\
\hline Intensity Threshold MEDIUM (Lower Limit) & 235 \\
\hline Intensity Threshold STRONG (Upper Limit) & 235 \\
\hline Intensity Threshold STRONG (Lower Limit) & 0 \\
\hline Intensity Threshold Negative Pixels & -1 \\
\hline
\end{tabular}

Supplementary Table 3. Color deconvolution macro specifications for pT181, pT205, pT217, and pT231 stained sections.

\begin{tabular}{|l|l|}
\hline Algorithm & Color Deconvolution \\
\hline Version & 9.1 \\
\hline View Width & 1000 \\
\hline View Height & 1000 \\
\hline Overlap Size & 0 \\
\hline Image Zoom & 1. \\
\hline Classifier & None \\
\hline Class List & \\
\hline Classifier Neighborhood & 0 \\
\hline Pixel Area (millimeter-squared) & $2.52506 \mathrm{e}-007$ \\
\hline Color Channel to Quantitate & 3 \\
\hline Markup Image Type & 0 \\
\hline Weak Positive Threshold & 235 \\
\hline Medium Positive Threshold & 180 \\
\hline Strong Positive Threshold & 180 \\
\hline Black Threshold & 0 \\
\hline Color(1) Red OD & 0.65 \\
\hline Color(1) Green OD & 0.704 \\
\hline Color(1) Blue OD & 0.286 \\
\hline Color(2) Red OD & $7.2 \mathrm{e}-002$ \\
\hline Color(2) Green OD & 0.99 \\
\hline Color(2) Blue OD & 0.105 \\
\hline Color(3) Red OD & 0.341 \\
\hline Color(3) Green OD & 0.575 \\
\hline Color(3) Blue OD & 0.743 \\
\hline & \\
\hline
\end{tabular}


Upon generating the custom designed macros for each tau antibody, we recognized that color deconvolution preferentially identified tau staining better than positive pixel count for pT205 and pT217. In contrast, positive pixel count preferentially identified tau staining better than positive pixel count for pT181 and pT231 compared to color deconvolution. These differences arise due to sensitivity of the underlying algorithm. Color deconvolution works best in recognizing a large range of staining intensity whereas positive pixel count excels in recognizing lighter staining. Positive pixel count results (Table 1) are used throughout the manuscript for ease of comparison. Color deconvolution results are detailed in Supplementary Table 4. A comparison of color deconvolution and positive pixel count is illustrated in Supplementary Figure 1.

Supplementary Table 4. Positive pixel count burden.

\begin{tabular}{|c|c|c|c|c|c|c|c|}
\hline Characteristic & Braak I & Braak II & Braak III & Braak IV & Braak V & Braak VI & p-value \\
\hline \multicolumn{8}{|c|}{ Whole hippocampus measures } \\
\hline \multicolumn{8}{|c|}{ Color Deconvolution } \\
\hline pT181 burden, $\%$ & $0.58(0.27,4.6)$ & $1.3(0.21,3.9)$ & $0.94(0.43,1.9)$ & $1.8(1.4,4.7)$ & $4.2(0.77,5.2)$ & $6.1(5.7,6.8)$ & $<0.001$ \\
\hline pT205 burden, $\%$ & $0.31(0.12,0.48)$ & $0.12(0.031,3.1)$ & $1.7(0.83,3.6)$ & $5.6(1.6,7.3)$ & $5.7(4.7,7.3)$ & $6.2(4.1,7.2)$ & $<0.001$ \\
\hline pT217 burden, $\%$ & $0.51(0.26,1.2)$ & $0.41(0.049,5.0)$ & $3.4(1.9,7.0)$ & $11(3.3,12)$ & $9.2(7.4,12)$ & $14(6.2,17)$ & $<0.001$ \\
\hline pT231 burden, $\%$ & $0.17(0.10,0.32)$ & $0.079(0.024,1.8)$ & $1.2(0.63,2.4)$ & $4.5(1.8,5.8)$ & $6.1(3.0,9.3)$ & $8.3(4.6,11)$ & $<0.001$ \\
\hline \multicolumn{8}{|l|}{ CA1 measures } \\
\hline \multicolumn{8}{|c|}{ Color Deconvolution } \\
\hline pT181 burden, $\%$ & $0.39(0.12,1.7)$ & $0.73(0.091,1.5)$ & $0.94(0.38,1.9)$ & $1.9(1.5,6.9)$ & $4.6(1.1,6.7)$ & $7.1(2.6,10)$ & $<0.001$ \\
\hline pT205 burden, $\%$ & $0.38(0.19,1.3)$ & $0.14(0.031,4.2)$ & $2.3(1.3,5.7)$ & $7.6(2.2,11)$ & $9.0(7.6,11)$ & $8.9(5.2,12)$ & $<0.001$ \\
\hline pT217 burden, $\%$ & $0.48(0.39,2.1)$ & $0.25(0.044,6.4)$ & $4.3(2.7,12)$ & $18(4.1,19)$ & $14(11,17)$ & $21(7.3,24)$ & $<0.001$ \\
\hline pT231 burden, $\%$ & $0.18(0.16,0.61)$ & $0.082(0.023,2.3)$ & $1.5(1.1,4.4)$ & $6.8(2.0,10)$ & $9.5(3.9,15)$ & $11(4.9,18)$ & $<0.001$ \\
\hline \multicolumn{8}{|c|}{ Subiculum measures } \\
\hline \multicolumn{8}{|c|}{ Color Deconvolution } \\
\hline pT181 burden, $\%$ & $0.47(0.21,3.1)$ & $1.1(0.12,2.2)$ & $1.2(0.56,2.2)$ & $3.0(2.4,6.9)$ & $5.5(1.4,7.3)$ & $11(6.6,13)$ & $<0.001$ \\
\hline pT205 burden, $\%$ & $0.63(0.17,0.73)$ & $0.16(0.037,6.3)$ & $3.4(2.0,6.8)$ & $10(3.9,11)$ & $10(8.1,15)$ & $12(7.0,15)$ & $<0.001$ \\
\hline pT217 burden, $\%$ & $0.96(0.42,1.7)$ & $0.41(0.056,11)$ & $7.2(4.8,13)$ & $21(7.6,25)$ & $15(13,25)$ & $29(12,33)$ & $<0.001$ \\
\hline pT231 burden, \% & $0.34(0.20,0.54)$ & $0.098(0.028,4.2)$ & $2.4(1.8,3.6)$ & $9.5(5.1,11)$ & $11(6.0,17)$ & $17(5.9,22)$ & $<0.001$ \\
\hline
\end{tabular}


bioRxiv preprint doi: https://doi.org/10.1101/2021.08.25.457363; this version posted August 26, 2021. The copyright holder for this preprint (which was not certified by peer review) is the author/funder, who has granted bioRxiv a license to display the preprint in perpetuity. It is made available under aCC-BY-NC 4.0 International license.

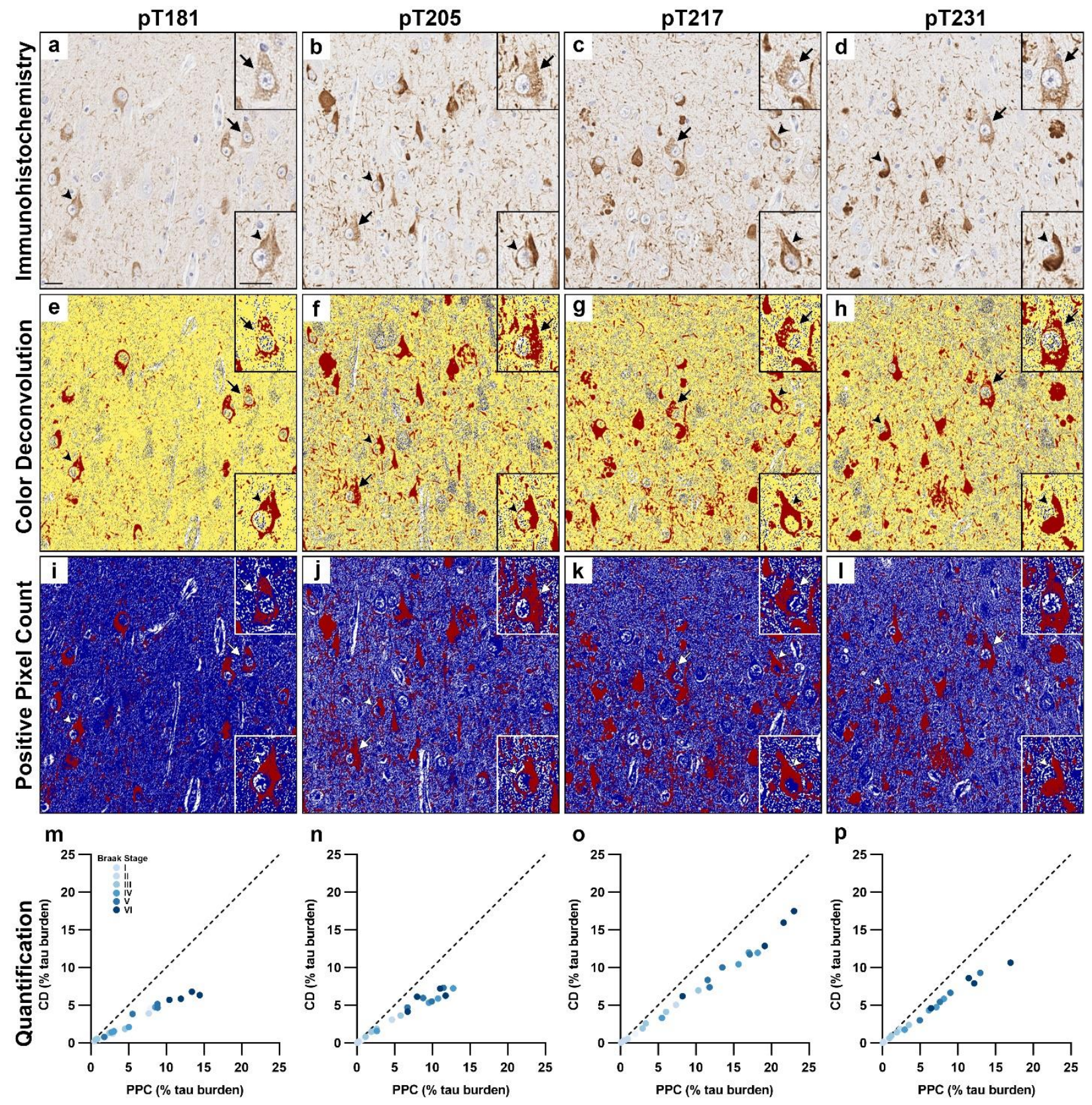

Supplementary Figure 1. Comparison of color deconvolution and positive pixel count. Immunohistochemistry of the CA1 region from case 20 stained for a pT181, b pT205, c pT217, and d pT231. Color deconvolution macro overlay for e pT181, f pT205, g pT217, and $\mathbf{h}$ pT231. Positive pixel count macro overlay for i pT181, j pT205, k pT217, and $\mathbf{l}$ pT231. Comparison of color deconvolution and positive pixel count macros for $\mathbf{m}$ pT181, $\mathbf{n}$ pT205, o pT217, and p pT231. Images are from case 20. Dotted line represents the line of equality $(y=x)$. Arrow, earlier tangle maturity level (i.e. pretangle or intermediary 1); arrowhead, mature tangle. Scale bar measures 25 $\mu \mathrm{m}$. 
bioRxiv preprint doi: https://doi.org/10.1101/2021.08.25.457363; this version posted August 26, 2021. The copyright holder for this preprint (which was not certified by peer review) is the author/funder, who has granted bioRxiv a license to display the preprint in perpetuity. It is made available under aCC-BY-NC 4.0 International license.
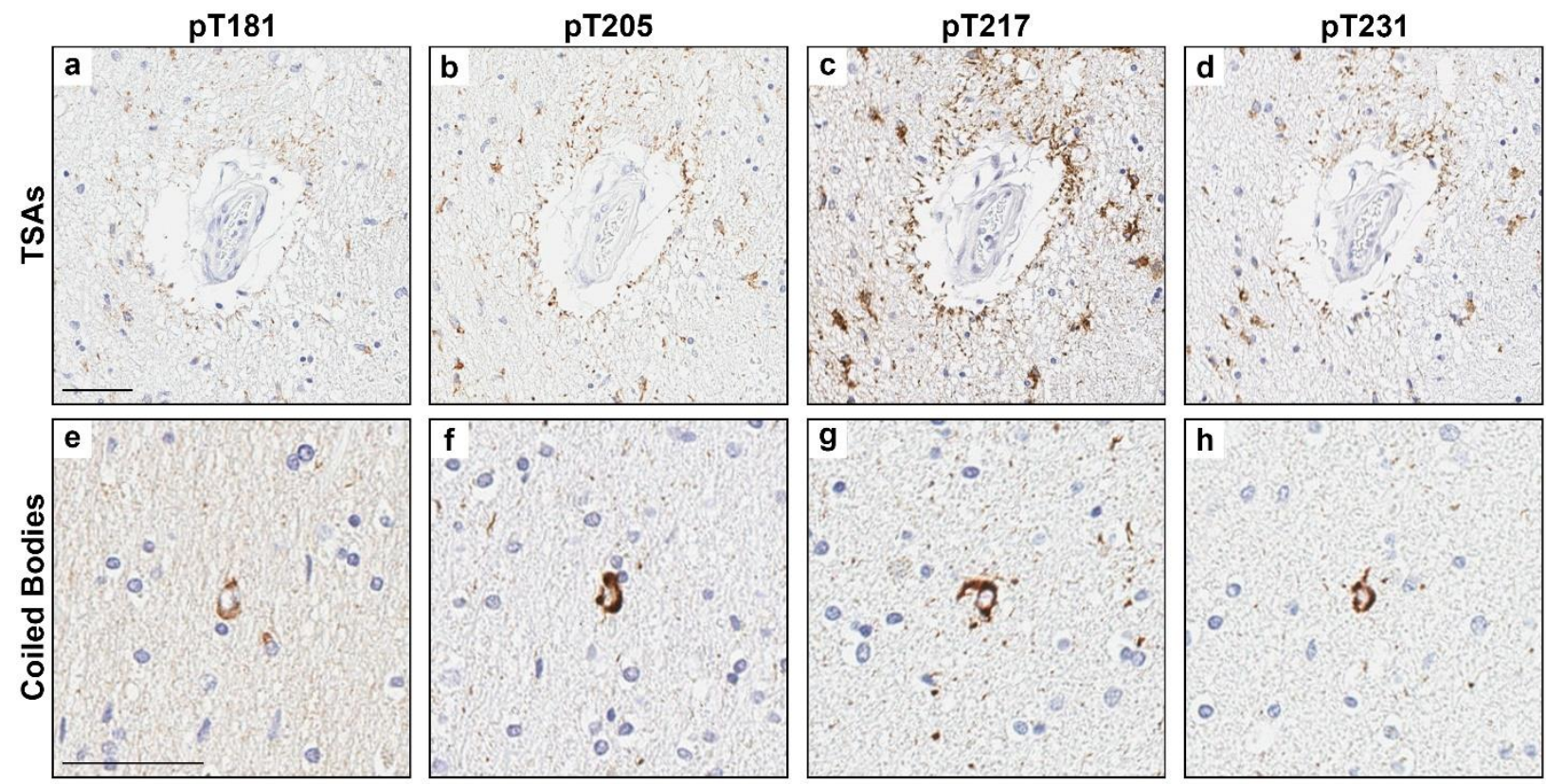

Supplementary Figure 2. Examples of additional tau pathology observed with each phosphorylated tau site. a-d Thorn shaped astrocytes (TSAs), a feature of ARTAG (case 12) and e-h Coiled bodies, a feature of grains disease (case 18). a, e were stained with the pT181 antibody. b, f were stained with the pT205 antibody. $\mathbf{c}, \mathbf{g}$ were stained with the pT217 antibody. $\mathbf{d}, \mathbf{h}$ were stained with the pT231 antibody. Scale bar measures $50 \mu \mathrm{m}$. 